Federal Reserve Bank of Dallas

Globalization and Monetary Policy Institute

Working Paper No. 237

http://www.dallasfed.org/assets/documents/institute/wpapers/2015/0237.pdf

\title{
Financial Frictions and Policy Cooperation: A Case with Monopolistic Banking and Staggered Loan Contracts*
}

\author{
Ippei Fujiwara \\ Keio University and Australian National University \\ Yuki Teranishi \\ Keio University \\ April 2015
}

\begin{abstract}
Do financial frictions call for policy cooperation? This paper investigates the implications of simple financial frictions, monopolistic banking together with staggered loan contracts, for monetary policy in open economies in the linear quadratic (LQ) framework. Welfare analysis shows that policy cooperation improves social welfare in the presence of such financial frictions. There also exist long-run gains from cooperation in addition to these by jointly stabilizing inefficient fluctuations over the business cycle, that are usually found in models with price rigidities. The Ramsey optimal steady states differ between cooperation and noncooperation. Such gains from cooperation arise irrespective of the existence of international lending or borrowing.
\end{abstract}

JEL codes: E50, F41

\footnotetext{
* Ippei Fujiwara, Faculty of Economics, Keio University, 2-15-45 Mita, Minato-ku, Tokyo 108-8345 Japan. ippei.fujiwara@anu.edu.au. Yuki Teranishi, Faculty of Business and Commerce, Keio University, 2-15-45 Mita, Minato-ku, Tokyo 108-8345 Japan. yukitera@fbc.keio.ac.jp. Formerly circulated as Financial Stability in Open Economies. The authors thank the editor Giancarlo Corsetti and two anonymous referees for useful comments. We have also benefited from discussions with Kosuke Aoki, Pierpaolo Benigno, Martin Bodenstein, Larry Christiano, Richard Dennis, Bianca De Paoli, Marty Eichenbaum, Takeo Hoshi, Gunes Kamber, Jinill Kim, Federico Mandelman, Tomoyuki Nakajima, Stefan Niemann, Maury Obstfeld, Bruce Preston, Lars Svensson, Cedric Tille, Mike Woodford, and seminar and conference participants at the University of Bonn, Hitotsubashi University, FRB Atlanta, Bank of Korea, University of Zurich, Victoria University of Wellington, Reserve Bank of New Zealand, Kyoto University and National University of Singapore. Fujiwara gratefully acknowledges financial support from the Murata Science Foundation. The views in this paper are those of the authors and do not necessarily reflect the views of the Federal Reserve Bank of Dallas or the Federal Reserve System.
} 


\section{Introduction}

The recent global financial crisis has renewed interest in the potential of policy cooperation. In order for the global economy to recover, the need for policy cooperation is now a topic of discussion for leaders in major policy institutions. ${ }^{1}$ Academic studies, however, do not usually emphasize the importance of cooperation in stabilization policies. ${ }^{2}$ What causes these divergent views on policy prescriptions during the global financial crisis?

Perri and Quadrini (2011) emphasize the importance of financial frictions in explaining the unprecedented degree of business cycle synchronization across different countries during the recent global financial crisis. In this paper, we tackle this problem by investigating the implications of simple financial market imperfections on monetary policy in open economies. For this purpose, we extend the standard new open economy macroeconomics (NOEM) model a la Clarida, Gali, and Gertler (2002) or Benigno and Benigno (2003, 2006), to incorporate an imperfectly competitive banking sector as examined in Kobayashi (2008), Teranishi (2015), Mandelman (2010, 2011), and Fujiwara and Teranishi (2011). The banking sector of our model has three features: a cost channel, monopoly power by banks over loan rate settings, and staggered loan contracts. Gerali, Neri, Sessa, and Signoretti (2010) estimate a similar model to ours, where monopolistic banking and sticky loan rates are incorporated in a prototypical dynamic stochastic general equilibrium (DSGE) model, in order to quantify the contribution of shocks originating from financial frictions to the slowdown during the recent global financial crisis.

Firms need to borrow working capital from private banks in advance to finance wage

\footnotetext{
${ }^{1}$ Dr. John Lipsky, Acting Managing Director of the IMF, stated on 21 June 2011, "A second success is the remarkable increase in global policy cooperation that has taken place in the wake of the 2008-09 global financial crisis. When the world last faced such grave danger - during the Great Depression - countries acted in their own, perceived self-interest with beggar-thy-neighbor policies that in fact deepened the downturn. This time, countries acted together to tackle the crisis."

${ }^{2}$ Corsetti, Dedola, and Leduc (2010) conclude that, "[i]n welfare terms, the gains from cooperation are close to zero. Indeed, the literature has presented numerical assessments of the benchmark model under the complete markets that do not generate appreciable quantitative welfare gains from coordinating policies, relative to optimal stabilization pursued by independent policy makers (engaging in strategic manipulation of terms of trade)."
} 
bills. Barth and Ramey (2002) and Ravenna and Walsh (2006) empirically demonstrate the importance of this cost channel in monetary policy transmission in the US. Each bank is assumed to be in a long-term relationship with each intermediate-goods producing firm. Thus, banks have monopoly power over loan rate settings. Gropp and Kashyap (2010), van Leuvensteijn, Sorensen, Bikker, and van Rixtel (2013) and Mandelman (2010, 2011) explore the importance of bank competitions on loan rate settings. Finally, dynamic frictions in the financial market are captured by staggered loan contracts, that follow the Calvo (1983) - Yun (1996) framework.

Stickiness in loan rate contracts is reported by many studies, as Slovin and Sushka (1983) and Berger and Udell (1992) for the U.S., Sorensen and Werner (2006) and Gambacorta (2008) for the Euro area, and the Bank of Japan's Financial System Reports for the Japanese economy. ${ }^{3}$ Their explanations rely on credit rationing during recession. There are, however, other aspects relating to stickiness in loan rates. For example, the Bank of Japan's Financial System Reports show that the duration of fixed loan contracts tends to be very long. Also, Graham and Wright (2007) report that a significant proportion of interest rate payments in some European countries are at a fixed rate. Furthermore, they note that "[t]he associated debt contracts are almost always written in nominal terms, have quite significant associated transactions costs and as a consequence are renegotiated relatively infrequently." 4

We then use a NOEM model with such financial frictions to analyze the optimal

\footnotetext{
${ }^{3}$ For the US, using micro level data, Slovin and Sushka (1983) and Berger and Udell (1992) show that it takes two or more quarters for the private banks to adjust loan interest rates.

For the Euro area, Sorensen and Werner (2006) estimate the incompleteness in the pass-through from the policy interest rate to loan interest rates in an error correction model using macro data. They further show that the degree of the incomplete pass-through significantly differs among countries. Gambacorta (2008) conducts similar analysis for Germany and shows the existence of sticky adjustment in loan interest rates.

For Japan, according to Bank of Japan's Financial System Reports published in March 2007 and 2008, the major city banks need five quarters and the local banks seven quarters to adjust loan interest rates.

${ }^{4}$ Several studies provide empirical evidences behind these infrequent negotiations, for example, Hannan and Berger (1991) for menu costs, Berger and Udell (1992) for implicit contracts and Calem, Gordy, and Mester (2006) for switching costs.
} 
monetary policy under both cooperation and noncooperation. In order to understand how simple financial frictions as explained above may alter gains from cooperation, a linear quadratic (LQ) approach is employed. The second order approximated welfare metric following Benigno and Woodford (2005) and Benigno and Benigno (2006) is also derived.

Staggered loan contracts under monopolistic competition in the banking sector create dispersion in loan rates when a shock hits the economy. Since labor supply is tightly linked to loan rates due to the working capital loan, this results in inefficient allocations in labor among ex post symmetric firms. Consequently, similarly to the case with price rigidities, dispersion in loan rates works as if it were a negative technology shock. The role of the central bank is to reduce welfare loss stemming from such dispersion in loan rates and the working capital loan.

Welfare analysis shows that there are both long-run and short-run gains in cooperation. Steady state welfare becomes higher under cooperation. Under noncooperation, each central bank has long-term incentives to raise loan interest rates. This is because high interest rates reduce labor supply via the cost channel. This result is similar to the one obtained in Cooley and Quadrini (2003). Over the business cycle, there also exist gains from cooperation when the global economy is subject to markup shocks. This is because the terms of trade externality, where each country attempts to manipulate the terms of trade in its favor, is not internalized under noncooperation. ${ }^{5}$ These results hold regardless of the existence of international lending or borrowing. Unless there is friction in international financial transactions, neither international lending nor borrowing makes any difference to the case in which only domestic financial transactions are allowed.

The rest of the paper is structured as follows. Previous studies with similar banking sectors to ours in a dynamic general equilibrium framework are summarized in Section

\footnotetext{
${ }^{5}$ The mechanism behind this result is similar to the one in Benigno and Benigno (2006) with sticky prices.
} 
2. Section 3 derives the model used in this paper and displays its dynamic properties. Section 4 solves the equilibrium under the Ramsey optimal monetary policy in both cooperative and noncooperative regimes. Section 5 derives the quadratic loss functions around the Ramsey optimal steady states obtained in Section 4. These are the welfare measures that central banks aim to minimize. We also investigate the nature of the optimal monetary policy in open economies with financial frictions. Section 6 extends the basic model to cases with international lending and borrowing. Finally, Section 7 summarizes the findings of this paper and introduces possible future extensions of this paper.

\section{Monopolistic Banking and Staggered Loan Con- tracts}

Nominal contracts together with infrequent renegotiation are commonly observed in many countries. Thus, the stickiness of loan rates together with imperfect competition in the banking sector are potentially important mechanisms in accounting for the data. Several previous studies incorporate a similar banking sector in a dynamic general equilibrium framework.

Gerali, Neri, Sessa, and Signoretti (2010), Mandelman (2010, 2011) and Fujiwara and Teranishi (2011) develop models with an imperfectly competitive financial sector. They all conclude that an imperfectly competitive banking sector contributes to a better fit of the model to the data. Gerali, Neri, Sessa, and Signoretti (2010) provide empirical evidence of the stickiness in loan contracts in this vein. They estimate the prototypical new Keynesian model, a la Smets and Wouters (2003, 2007) and Christiano, Eichenbaum, and Evans (2005), and extend to replicate the aforementioned features with a monopolistic banking sector and loan rate stickiness. Shocks stemming from the banking 
sector explain the major part of the contraction in the recent financial crisis. Mandelman $(2010,2011)$ finds that the incorporation of a monopolistic banking sector increases the volatility of real variables and amplifies the business cycle. Countercyclical bank markups generated from strategic limit pricing - aimed at protecting retail niches from potential competitors - increases the model's fit to the data in developing economies. Fujiwara and Teranishi (2011) explain the persistence of the real exchange rate by incorporating an imperfectly competitive financial sector. Also, Ravenna and Walsh (2006) report empirical evidence of a direct interest rate effect on inflation where marginal costs are affected both by real wages divided by the productivity and nominal interest rates.

On implications of such financial frictions on monetary policy, Ravenna and Walsh (2006) introduce the cost channel into an otherwise standard new Keynesian model in closed economy. The optimal monetary policy under the cost channel faces trade-off between inflation and output gap stabilization even with the IS shocks. Cooley and Quadrini (2003) hint that the decline in interest rates after the advent of Euro can be explained by monetary cooperation in a two-country model with the cost channel. No study, however, has investigated whether financial market imperfections call for policy cooperation not only in the long-run but also over business cycles.

Such mechanisms can also replicate one of the important characteristics of monetary policy, interest rate smoothing. Woodford (2003) explains this through the history dependent policy under commitment. Graham and Wright (2007), Kobayashi (2008), and Teranishi (2015) demonstrate that rigidities in loan rate dynamics can also necessitate interest rate smoothing as the optimal policy reaction to shocks. ${ }^{6}$ Fujiwara and Teranishi (2011) also emphasize that the sticky loan mechanism can produce hump-shaped

\footnotetext{
${ }^{6}$ Contrary to Kobayashi (2008), and Teranishi (2015), stickiness in interest rates is imposed on consumers in Graham and Wright (2007). Thus, the loan interest rate in the IS curve is sticky in Graham and Wright (2007), while in our model, that in the Phillips curve is sticky.

Also, Graham and Wright (2007) do not conduct welfare analysis but show an interesting result on monetary policy. Low interest rates are maintained even after inflationary shocks hit the economy under sticky debt contracts.
} 
responses to many structural shocks including monetary policy shock. As previous literature on monetary policy transmission mechanism using the Vector Autoregressive models as represented by Christiano, Eichenbaum, and Evans (1999) shows, the ability to produce hump-shaped responses is considered to be important for the dynamic stochastic general equilibrium model. As a result, many studies using the dynamic stochastic general equilibrium incorporate habit formation in consumption or investment growth adjustment costs as examined in Christiano, Eichenbaum, and Evans (2005). Sticky loan rates can have hump-shaped properties without relying on these mechanisms.

For a positive analysis of financial market imperfections, many studies employ the financial accelerator mechanism of Bernanke, Gertler, and Gilchrist (1999) in the dynamic stochastic general equilibrium framework. In the financial accelerator mechanism, net worth as the state variable causes the deviations of loan rates from the policy interest rate. In our model, instead of net worth dynamics, the wedge between the loan rate and the policy rate arises due to imperfect competition in firms and thus banks. Accordingly, the dynamics of loan rates are created by staggered loan contracts. The consequences are, however, similar. A shock related to financial market imperfections eventually results in an increase in the cost of goods production. ${ }^{7}$ The benefit of our approach is that the nature of optimal monetary policy can be understood analytically and therefore intuitively..$^{8}$

\section{Model}

This section describes a two country model with financial frictions. There are four agents in two symmetric countries: consumers, firms, private banks, and central banks. We first display the problems solved by each agent and then summarize equilibrium conditions.

\footnotetext{
${ }^{7}$ This is also true for the model with collateral constraints as in Kiyotaki and Moore (1997).

${ }^{8}$ For numerical analysis on optimal monetary policy in open economies with such financial frictions, see Bodenstein, Guerrieri, and LaBriola (2014).
} 
The main model does not allow banks to lend and borrow internationally. Still, financial shocks spill over internationally, through exports and imports. Thus, financial frictions in one country can alter the dynamics of endogenous variables in the other country. The extension of the main model to international lending and borrowing will be discussed in Section 6.

\subsection{Consumers}

A representative consumer in the home country $H$ maximizes welfare $W_{t}$ :

$$
W_{t} \equiv \mathbb{E}_{t} \sum_{T=t}^{\infty} \beta^{T-t}\left\{u\left(C_{T}\right)-\int_{0}^{1} v\left[l_{T}(h)\right] \mathrm{d} h\right\}
$$

where $\mathbb{E}_{t}$ is the expectations operator conditional on the state of nature at date $t$ and $\beta \in[0,1)$ is the subjective discount factor. The functions $u$ and $v$ are increasing in the consumption index $C_{t}$ and the labor supply $l_{t}$, respectively. $l_{t}(h)$ denotes the labor supplied to intermediate-goods producing firm $h$.

The budget constraint is given by

$$
\begin{aligned}
P_{t} C_{t}+\mathbb{E}_{t}\left[X_{t, t+1} B_{t+1}\right]+D_{t} \leq & B_{t}+\left(1+i_{t-1}\right) D_{t-1}+\int_{0}^{1} w_{t}(h) l_{t}(h) \mathrm{d} h \\
& +\Pi_{t}^{B}+\Pi_{t}^{F}-T_{t},
\end{aligned}
$$

where $P_{t}$ is the aggregate consumer price index, $B_{t}$ is the Arrow security, $D_{t}$ is the deposit to the private banks, $i_{t}$ is the nominal interest rate set by the central bank from $t-1$ to $t, w_{t}$ is the nominal wage, $\Pi_{t}^{B}=\int_{0}^{1} \Pi_{t}^{B}(h) \mathrm{d} h$ is the nominal dividend from the ownership of the private banks in the home country, $\Pi_{t}^{F}=\int_{0}^{1} \Pi_{t}^{F}(h) \mathrm{d} h$ is the nominal dividend from the ownership of intermediate-goods producing firms in the home country, $X_{t, t+1}$ is the stochastic discount factor, and $T_{t}$ is the lump sum tax. ${ }^{9}$

\footnotetext{
${ }^{9}$ The results obtained in this paper will not change even if a deposit to foreign banks or ownership of foreign firms and banks is allowed.
} 
Because a complete financial market between the two countries is assumed, consumers in each country can internationally trade the state contingent securities to insure against country-specific shocks. Consequently, consumers in both countries encounter a unique discount factor. Assuming a complete international financial market in the presence of financial market imperfections may seem unreasonable. These are, however, thought to be important ingredients in explaining economic developments during the recent global financial crisis, in particular, the significant synchronization of the business cycles across different countries. Perri and Quadrini (2011) explain this unprecedented degree of synchronization using a model with credit shocks (financial market imperfections) under complete international financial markets.

\subsection{Firms}

\subsubsection{Intermediate-goods producer}

Intermediate-goods producer $h$ produces a differentiated intermediate good $y_{t}$ using the differentiated labor:

$$
y_{t}(h)+y_{t}^{*}(h)=f\left[l_{t}(h)\right]
$$

and needs to borrow loans $q_{t}$ to finance labor compensation:

$$
q_{t}(h)=R_{t}(h) w_{t}(h) l_{t}(h)
$$

where $R_{t}$ is gross loan rates. The intermediate-goods producer $h$ sets prices in both domestic and foreign markets under the law of one price: ${ }^{10}$

$$
p_{t}(h)=S_{t} p_{t}^{*}(h)
$$

\footnotetext{
${ }^{10}$ There is no need to assume either producer currency pricing or local currency pricing as there is no price stickiness.
} 
to maximize the profit $\Pi_{t}^{F}$ :

$$
\Pi_{t}^{F}(h)=\left(1+\tau_{t}\right)\left[p_{t}(h) y_{t}(h)+S_{t} p_{t}^{*}(h) y_{t}^{*}(h)\right]-R_{t}(h) w_{t}(h) l_{t}(h)
$$

where the asterisk $*$ denotes foreign variables. $p_{t}$ and $p_{t}^{*}$ denote prices to home and foreign markets, respectively. ${ }^{11} S_{t}$ is nominal exchange rates.

$\tau_{t}$ is the sales subsidy. With this time-varying sales subsidy financed by the lump-sum tax, the markup shock $\mu_{t}$ is defined as

$$
\exp \left(\mu_{t}\right) \equiv \overbrace{\frac{\sigma}{\sigma-1}}^{\text {ss markup }} \overbrace{\frac{1}{1+\tau_{t}}}^{\text {time-variation }},
$$

where $\sigma$ denotes the elasticity of substitution between differentiated intermediate goods. $\mu_{t}$ can capture time-variation in the markups. This is a specification following Benigno and Benigno (2006) and creates inefficient fluctuations in the marginal rate of substitution between consumption and goods production. The same outcome is obtained by using other specifications: time-varying monopoly power of wage setters as in Clarida, Gali, and Gertler (2002) and Woodford (2003); a time-varying elasticity of substitution as in Giannoni (2014).

Under the current settings, domestic (foreign) firms borrow only from domestic (foreign) banks. This assumption will be relaxed later in Section 6 to check whether international lending and borrowing alter our main results.

\footnotetext{
${ }^{11}$ In this paper, sticky prices are not assumed to solely concentrate on the role of the financial frictions on policy cooperation. There is a trade-off between price stability and financial stability with sticky prices. For details of this trade-off, see Kobayashi (2008) and Teranishi (2015).
} 


\subsubsection{Final-goods producer}

A final consumption goods producer minimizes the total cost:

$$
P_{H, t} Y_{H, t}+P_{F, t} Y_{F, t}
$$

subject to the following production technology:

$$
Y_{t} \equiv\left(\frac{Y_{H, t}}{\psi}\right)^{\psi}\left(\frac{Y_{F, t}}{1-\psi}\right)^{1-\psi}
$$

where $\psi(0 \leq \psi \leq 1)$ denotes the home bias. $\psi$ is set to 0.5 since symmetry between two countries is assumed. Goods produced in the domestic country $Y_{H, t}$ and those produced in the foreign country $Y_{F, t}$ are defined, respectively, as

$$
Y_{H, t} \equiv\left[\int_{0}^{1} y_{t}(h)^{\frac{\sigma-1}{\sigma}} \mathrm{d} h\right]^{\frac{\sigma}{\sigma-1}}
$$

and

$$
Y_{F, t} \equiv\left[\int_{0}^{1} y_{t}\left(h^{*}\right)^{\frac{\sigma-1}{\sigma}} \mathrm{d} h^{*}\right]^{\frac{\sigma}{\sigma-1}}
$$

\subsection{Private Banks}

There is a continuum of private banks in each country located over $[0,1]$. Each private bank collects deposits from consumers in its country given saving interest rates. Each bank $h$ is in a long-term relationship with each intermediate-goods producing firm $h$. This follows a segmented banking system assumed in such previous studies as Kobayashi (2008), Andrés and Arce (2012) and Mandelman (2010, 2011). As a result, it sets differentiated nominal loan interest rates according to their individual loan demand curves. A differentiated nominal loan interest rate applies to differentiated intermediate-goods producers. Thus, within this segmented environment, private banks maintain monopoly 
power over the loan interest rate determination. ${ }^{12}$

In addition, each bank resets its loan interest rates with probability $1-\phi$ following the Calvo (1983) - Yun (1996) framework as examined in Teranishi (2015) and Fujiwara and Teranishi (2011). Due to staggered loan contracts between firms and private banks, private banks end up fixing nominal loan interest rates for a certain period. Staggered loan contracts also generate dispersion in loan interest rates, which result in welfare costs, which will be explained in detail.

The private bank $h$ sets the loan interest rate to maximize the present discounted value of profit:

$$
\mathbb{E}_{t} \sum_{T=t}^{\infty} \phi^{T-t} X_{t, T} \Pi_{T}^{B}(h)
$$

where

$$
\Pi_{t}^{B}(h)=q_{t}(h)\left[\left(1+\tau_{t}\right) R_{t}(h)-\left(1+i_{t}\right) \exp \left(u_{t}\right)\right]
$$

$u_{t}$ denotes the loan premium shock.

Note that goods prices are flexible in this model. In addition, the monetary authority does not adjust nominal interest rates on deposits $i_{t}$ with a Taylor rule arrangement a typical feature in the NOEM setup, although such an arrangement is indeed possible. Nominal interest rates on deposits are given by the optimal monetary policy discussed below.

\subsubsection{Summary: Financial Markets}

In this economy, the benevolent central bank determines nominal interest rates $i_{t}$ to maximize social welfare. Households take $i_{t}$ as deposit interest rates and smooth consumption through intertemporal optimization. Banks in the monopolistically competitive market borrow from households as deposits or loanable funds $D_{t}$ with deposit interest rates $i_{t}$,

\footnotetext{
${ }^{12}$ Almost identical results are obtained with the assumption of the monopolistically competitive banking sector as examined in Teranishi (2015), Gerali, Neri, Sessa, and Signoretti (2010) and Fujiwara and Teranishi (2011).
} 
and lend to firm $h$ with lending rates $R_{t}(h)$.

At the beginning of the period, banks receive deposits and lend funds to firms. At the end of the period, they receive repayments from firms. If loan rates are flexible, lending and borrowing are determined by the intra-temporal optimization problem by private banks, which is similar to the standard static profit maximization problem by firms. ${ }^{13}$ When loan rates are sticky, firms solve the dynamic optimization problem to maximize the present discounted value of the profits as shown in equations (10) and (11). This is also analogous to the optimal price setting problem by firms under sticky prices in the standard new Keynesian model. With the possibility that firms may not be able change loan rates in the future $\phi$, optimal loan rate setting becomes forward-looking.

To focus on the role of financial frictions, prices are assumed to be flexible. It is therefore possible to assume that the central bank can directly control real (deposit) interest rates. ${ }^{14}$ The real interest rate set by the central bank in this manner, however, is usually different from that arising in the frictionless (efficient) economy, which can be called as the natural rate of interest on deposits. The natural rate of interest on deposits is determined through the consumption Euler equation:

$$
C_{t}^{-v}=\beta \mathbb{E}_{t} \frac{1+i_{t}}{\pi_{t+1}} C_{t+1}^{-v}=\beta \mathbb{E}_{t}\left(1+r_{t+1}\right) C_{t+1}^{-v}
$$

$r_{t+1}$ becomes the natural rate of interest on deposits when consumption is always at its efficient (natural) level. ${ }^{15}$

A wedge between the current deposit interest rate and the natural rate of interest on deposits may emerge after (real) shocks hit the economy. ${ }^{16}$ The central bank's role is

\footnotetext{
${ }^{13}$ The difference between a monopolistic banking sector with flexible loan contracts and a perfectly competitive banking sector is found only in the existence of the steady state markup in the former. No difference arises in dynamics.

${ }^{14}$ To be precise, as will be explained below, CPI inflation rates are left to be indeterminate, but CPI inflation expectations are uniquely pinned down through the consumption Euler equation.

${ }^{15} \mathrm{As}$ is the case with the standard new Keynesian model, consumption Euler equations are not included in central banks' welfare maximization problem since they are redundant.

${ }^{16}$ Shocks create a wedge between current loan rates and those under efficient economy. This will
} 
how to minimize this wedge in order to maximize social welfare. Thus, reactions by the central bank to shocks alter deposit interest rates, while loan interest rates adjust only gradually due to staggered loan contracts. As will become clearer, completely eliminating the effects from shocks to loan rates is not necessarily the optimal monetary policy.

Even if loan rates are flexible, the central bank can improve social welfare in this model. Changes in the level of loan rates lead to inefficient fluctuations in output (and therefore consumption eventually) under the working capital loan. Thus, flexibility in loan rates does not prevent the central bank from eliminating inefficient fluctuations in output by adjusting nominal interest rates to shocks.

\subsection{Preference and Parameter}

$u(\cdot)$ and $v(\cdot)$ are iso-elastic functions:

$$
u(c)=\frac{c^{1-v}}{1-v}
$$

and

$$
v(l)=l
$$

Firms are equipped with a linear production technology:

$$
f(l)=\exp \left(z_{t}\right) l
$$

where $z_{t}$ denotes the technology shock. Appendix A displays the detailed derivation for the system of equations.

eventually produce a wedge between current deposit rates and the natural rate of interest on deposits. The natural rate of interest is defined so that it corresponds to the policy interest rate as is convention in the standard new Keynesian model. 


\subsection{Market Clearing Conditions}

Equation (3) together with the foreign counterpart depict the market clearing conditions for intermediate goods. The market clearing conditions for final goods are simply

$$
C_{t}=Y_{t}
$$

and

$$
C_{t}^{*}=Y_{t}^{*}
$$

Financial markets clear when total deposits equal to total loans:

$$
\int_{0}^{1} q_{t}(h) \mathrm{d} h=D_{t}
$$

and net supply of the Arrow securities is zero:

$$
B_{t}=0
$$

\subsubsection{Welfare Costs}

The staggered loan contract creates dispersion in loan interest rates. With the working capital loan, loan rates are tightly linked with labor supply. Dispersion in loan rates leads to inefficient allocations of labor among ex post symmetric firms like price dispersion in the standard new Keynesian model.

Similarly to Yun (2005) for price dispersion, the relative loan rate dispersion is defined as

$$
\Delta_{t} \equiv \int_{0}^{1}\left[\frac{R_{t}(h)}{R_{t}}\right]^{-\sigma} \mathrm{d} h
$$


where $R_{t}$ is the average loan rates:

$$
R_{t} \equiv\left[\int_{0}^{1} R_{t}(h)^{1-\sigma} \mathrm{d} h\right]^{\frac{1}{1-\sigma}}
$$

Then, aggregating the resource constraints over $h$ leads to

$$
\psi \Delta_{t}\left(\frac{P_{t} Y_{t}}{P_{H, t}}+\frac{P_{t}^{*} Y_{t}^{*}}{P_{H, t}^{*}}\right)=\exp \left(z_{t}\right) l_{t} .
$$

Any dispersion of loan rates, namely $R_{t}(h) \neq R_{t}$, works as if it were a negative technology shock. $\Delta_{t}$ represents the welfare cost stemming from staggered loan contracts. For the details of the derivation, see Appendix A, in particular, equation (85).

\subsection{System of Equations}

11 equilibrium conditions below, together with the optimal monetary policy defined in the next section determine the optimal paths for $R, F, K, Y, R^{*}, F^{*}, K^{*}, l, l^{*}, \Delta, \Delta^{*}$, $i$ and $i^{*}$ :

$$
\begin{gathered}
{\left[\frac{1-\phi\left(\frac{R_{t-1}}{R_{t}}\right)^{1-\sigma}}{1-\phi}\right]^{\frac{1}{1-\sigma}} F_{t}=K_{t},} \\
F_{t}=1+\beta \phi \mathbb{E}_{t} \frac{Y_{t+1}^{1-v}}{Y_{t}^{1-v}}\left(\frac{R_{t}}{R_{t+1}}\right)^{1-\sigma} F_{t+1}, \\
K_{t}=\frac{\left(1+i_{t}\right) \exp \left(\mu_{t}\right) \exp \left(u_{t}\right)}{R_{t}}+\beta \phi \mathbb{E}_{t} \frac{Y_{t+1}^{1-v}}{Y_{t}^{1-v}}\left(\frac{R_{t}}{R_{t+1}}\right)^{-\sigma} K_{t+1}, \\
{\left[\frac{1-\phi\left(\frac{R_{t-1}^{*}}{R_{t}^{*}}\right)^{1-\sigma}}{1-\phi}\right]^{\frac{1}{1-\sigma}} F_{t}^{*}=K_{t}^{*},} \\
F_{t}^{*}=1+\beta \phi \mathbb{E}_{t} \frac{Y_{t+1}^{1-v}}{Y_{t}^{1-v}}\left(\frac{R_{t}^{*}}{R_{t+1}^{*}}\right)^{1-\sigma} F_{t+1}^{*},
\end{gathered}
$$




$$
\begin{gathered}
K_{t}^{*}=\frac{1+i_{t}^{*}}{R_{t}^{*}}+\beta \phi \mathbb{E}_{t} \frac{Y_{t+1}^{1-v}}{Y_{t}^{1-v}}\left(\frac{R_{t}^{*}}{R_{t+1}^{*}}\right)^{-\sigma} K_{t+1}^{*}, \\
\frac{Y_{t}^{1-v} \Delta_{t}}{\exp \left(\mu_{t}\right) R_{t}}=l_{t}, \\
\Delta_{t}=(1-\phi)\left[\frac{1-\phi\left(\frac{R_{t-1}}{R_{t}}\right)^{1-\sigma}}{1-\phi}\right]^{\frac{\sigma}{\sigma-1}}+\phi\left(\frac{R_{t-1}}{R_{t}}\right)^{-\sigma} \Delta_{t-1}, \\
\Delta_{t}^{*}=(1-\phi)\left[\frac{1-\phi\left(\frac{R_{t-1}^{*}}{R_{t}^{*}}\right)^{1-\sigma}}{1-\phi}\right]^{\frac{\sigma}{\sigma-1}}+\phi\left(\frac{R_{t-1}^{*}}{R_{t}^{*}}\right)^{-\sigma} \Delta_{t-1}^{*},
\end{gathered}
$$

and

$$
1=Y_{t}^{2 v} \exp \left(\mu_{t}\right)\left[\frac{R_{t}}{\exp \left(z_{t}\right)}\right] R_{t}^{*}
$$

Similarly to Yun (2005), equations (16) to (18) and equations (19) to (21) represent the recursive representations for domestic and foreign loan Phillips curves, respectively. The first-order log-linear approximation on these equations around the Ramsey optimal steady states $\left(\hat{x}_{t} \equiv \log \left(X_{t} / X\right) \approx\left(X_{t}-X\right) / X\right.$, where $X$ is the Ramsey optimal steady state value) leads to the domestic loan rate Phillips curve:

$$
\hat{R}_{t}-\hat{R}_{t-1}=\beta \mathbb{E}_{t}\left(\hat{R}_{t+1}-\hat{R}_{t}\right)+\frac{(1-\phi)(1-\beta \phi)}{\phi}\left(i_{t}+u_{t}+\mu_{t}-\hat{R}_{t}\right)
$$

and the foreign loan rate Phillips curve:

$$
\hat{R}_{t}^{*}-\hat{R}_{t-1}^{*}=\beta \mathbb{E}_{t}\left(\hat{R}_{t+1}^{*}-\hat{R}_{t}^{*}\right)+\frac{(1-\phi)(1-\beta \phi)}{\phi}\left(i_{t}^{*}-\hat{R}_{t}^{*}\right) .
$$

Equations (27) and (28) are analogous to the new Keynesian Phillips curve. Instead of inflation rates, which are defined as $\hat{\pi}_{t}=\hat{P}_{t}-\hat{P}_{t-1}$, here inflation rates for gross loan rates 
$\left(\hat{R}_{t}-\hat{R}_{t-1}\right)$ are determined by loan inflation expectation $\mathbb{E}_{t}\left(\hat{R}_{t+1}-\hat{R}_{t}\right)$ and (nominal) marginal costs of loan creation $\left(i_{t}+u_{t}+\mu_{t}-\hat{R}_{t}\right)$. Loan interest rates affect marginal costs with the presence of the cost channel as equations (4), (27) and (28) illustrate. Thus, contrary to the standard new Keynesian model, inflation rates (of loan rates) as well as the price level (of loan rates) are pinned down by the model. Consequently, backward-looking components in equations (27) and (28), namely $\hat{R}_{t-1}$ and $\hat{R}_{t-1}^{*}$, become the endogenous state variables in this model. Note also that steady states do not matter for linearized aggregate supply conditions.

Equations (23) and (25) show the dynamics of relative loan rate dispersion, which is defined in equation (14) and

$$
\Delta_{t}^{*} \equiv \int_{0}^{1}\left[\frac{R_{t}^{*}\left(h^{*}\right)}{R_{t}^{*}}\right]^{-\sigma} \mathrm{d} h^{*}
$$

Since each bank only resets its loan interest rates with probability $1-\phi$, equations (23) and (25) are derived from the definition of the average loan rates in equation (15) and

$$
R_{t}^{*} \equiv\left[\int_{0}^{1} R_{t}^{*}\left(h^{*}\right)^{1-\sigma} \mathrm{d} h^{*}\right]^{\frac{1}{1-\sigma}}
$$

As is well-known in the literatures with the new Keynesian model, relative price dispersion matters only under higher order than linear approximation. This is because with linear approximation,

$$
\hat{\Delta}_{t}=\hat{\Delta}_{t}^{*}=0
$$

Equations (22) and (24) are derived from the market clearing conditions for intermediate goods in equation (3) and its foreign counterpart. As is the case with the standard new Keynesian model, relative price dispersion terms in equations (14) and (29) act as if they were negative technology shocks. As a result, price stability, or loan rate stability in this paper, becomes the optimal monetary policy. 
Equation (26) is the market clearing condition for the final goods in equations (12) and (13) under the complete international financial market. This can be also expressed as log-deviation from the Ramsey optimal steady states as

$$
0=\mu_{t}+2 v \hat{Y}_{t}+\hat{R}_{t}-z_{t}+\hat{R}_{t}^{*}
$$

The consumption Euler equation for the domestic country:

$$
Y_{t}^{-v}=\beta\left(1+i_{t}\right) \mathbb{E}_{t}\left(\frac{Y_{t+1}^{-v}}{\pi_{t+1}}\right)
$$

and that for the foreign country:

$$
\left(Y_{t}^{*}\right)^{-v}=\beta\left(1+i_{t}^{*}\right) \mathbb{E}_{t}\left[\frac{\left(Y_{t+1}^{*}\right)^{-v}}{\pi_{t+1}^{*}}\right]
$$

can be included in addition to equilibrium conditions (16) to (26). These will determine CPI inflation expectations in both countries. In such a model, however, indeterminacy in inflation rates arises. In order to avoid this indeterminacy, a sticky price mechanism must be incorporated in intermediate goods firms' profit maximization problem in equations (6). This will, however, complicate the analysis, especially in open economies. Thus, nominal price rigidities are omitted from the model and CPI inflation rates are left to be indeterminate in this model.

In this economy, there are three distortions: suboptimally low production due to monopolistic rents, working capital loans, and staggered loan contracts. The first distortion is eliminated by an appropriate subsidy. The optimal monetary policy aims to minimize the welfare costs stemming from the second and the third distortions. 
Figure 1: Responses to Monetary Policy Shock
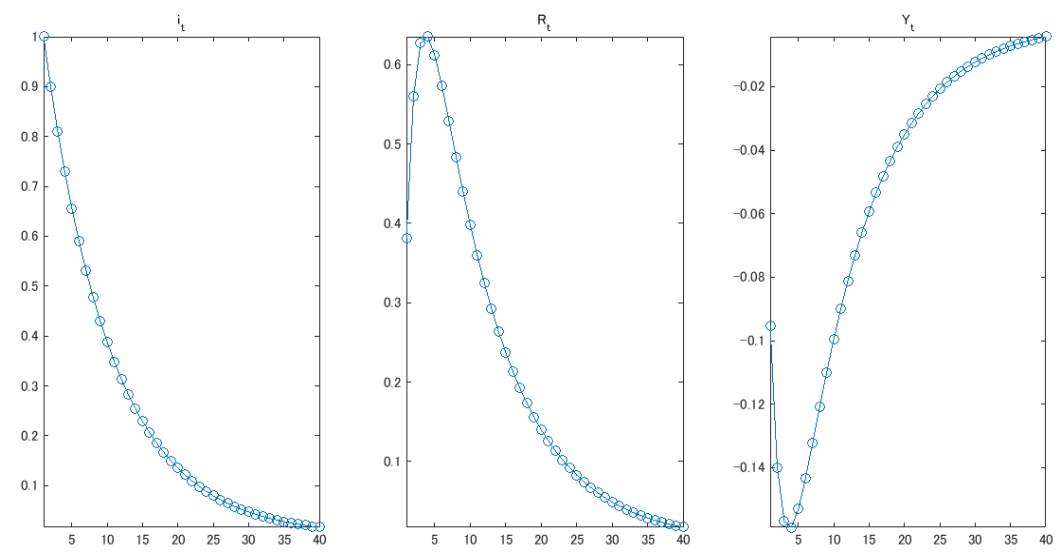

\subsection{Dynamic Properties}

Here, we display the dynamic property of this model to the monetary policy shock. Even though the model is quite simple and stylized, it can capture important properties in the monetary transmission mechanism: namely, the delayed responses in loan rates and hump-shaped responses of output and consumption.

In the simplest form, the linearized equilibrium conditions in equations (27), (28) and (30) given policy interest rates can determine the equilibrium paths for domestic loan rates $R_{t}$, foreign loan rates $R_{t}^{*}$ and final goods production (consumption in both domestic and foreign countries) $Y_{t}$. The existence of lagged loan rates in equations (27) and (28) and the absence of the determination of inflation rates give the model quite different implications regarding indeterminacy stemming from monetary policy rules. The model can have unique rational expectations equilibrium without monetary policy feedback rules.

Figure 1 illustrates the responses of these variables to a monetary policy shock or an increase in policy interest rates $i_{t}$, which is eventually deposit interest rates in the consumption Euler equation in (31). The parameters are calibrated as in Table 1. $\beta$ and $\sigma$ are taken from Steinsson (2008), and $\phi$ is the average value of loan rate stickiness 
Table 1: Parameter Values

\begin{tabular}{lll}
\hline \hline Parameters & Values & Explanation \\
\hline$\beta$ & 0.99 & Subjective discount factor \\
$v$ & 2 & Coefficient of relative risk aversionect to real interest rate \\
$\phi$ & 0.57 & Probability of loan interest rate change \\
$\sigma$ & 7.66 & Substitutability of differentiated consumption goods \\
\hline
\end{tabular}

across the countries estimated in Fujiwara and Teranishi (2011). The monetary policy shock follows an $\mathrm{AR}(1)$ process with a parameter of 0.9 .

Due to the existence of staggered loan contracts, the initial response of domestic loan rates becomes significantly smaller compared to changes in domestic policy interest rates. Thus, delayed responses on loan rates reported by such previous studies as Slovin and Sushka (1983), Berger and Udell (1992), Sorensen and Werner (2006), Graham and Wright (2007), Gambacorta (2008) and Gerali, Neri, Sessa, and Signoretti (2010) materialize in this model. In addition, the responses of $Y_{t}$, that is the final output and therefore consumption in both domestic and foreign countries, demonstrate humpshaped dynamics, often considered an important property for the dynamic stochastic general equilibrium model to replicate. Hump-shaped responses stem from lagged loan rates in equations (27) and (28) as endogenous state variables. Unlike the standard new Keynesian model with sticky prices, the level of nominal variables - price levels in the new Keynesian model and the levels of loan rates in our model - constrain real variables through the working capital loan.

The foreign loan rate Phillips curve in equation (28) contains only foreign loan and policy interest rates. A shock also only impacts upon domestic policy interest rates. Thus, foreign loan rates remain at a steady state level in this simulation. Through an increase in domestic loan rates, however, consumption in the foreign country also decreases due to the cost channel of monetary policy under the complete international financial market. We will consider optimal reactions by both domestic and foreign central 
banks in the following sections.

\section{Ramsey Policy}

In this section, the Ramsey optimal monetary policy under both cooperation and noncooperation will be discussed. There are two main aims of deriving the allocations under the Ramsey optimal monetary policy in this section: to compute the optimal Ramsey optimal steady state around which the model should be approximated, and to understand whether there are gains from cooperation in the long-run.

\subsection{Cooperation}

Under cooperation, two central banks aim to maximize global welfare together:

$$
\begin{aligned}
W_{t}+W_{t}^{*} & \equiv \mathbb{E}_{t} \sum_{T=t}^{\infty} \beta^{T-t}\left[\frac{C_{T}^{1-v}}{1-v}+\frac{\left(C_{T}^{*}\right)^{1-v}}{1-v}-\int_{0}^{1} l_{T}(h) \mathrm{d} h-\int_{0}^{1} l_{T}\left(h^{*}\right) \mathrm{d} h^{*}\right] \\
& =\mathbb{E}_{t} \sum_{T=t}^{\infty} \beta^{T-t}\left(\frac{2 Y_{T}^{1-v}}{1-v}-l_{T}-l_{T}^{*}\right)
\end{aligned}
$$

where equations (12) and (13) are substituted, subject to equilibrium conditions in equations (16) to (26). Appendix B provides all equilibrium conditions involving Lagrange multipliers on the constraints of this problem. These determine the allocations under the optimal monetary policy in cooperation.

\subsection{Noncooperation}

Under noncooperation, the game between two central banks must be well-defined. In particular, we must clarify the action of the opponent which is taken as given. In this paper, we solve the open-loop Nash equilibrium, where the domestic (foreign) central bank maximizes welfare of domestic (foreign) country given the policy interest rate in 
the foreign (domestic) country. Clarida, Gali, and Gertler (2002) assume output in the other country to be given, while producer price inflation rates in the other country are considered to be given in Benigno and Benigno (2003, 2006). In the model considered in this paper, there is neither country specific output nor inflation as can be seen in equations (16) to (26). Consequently, the natural variable to be given as exogenous to each central bank is the policy interest rate in the counterpart country.

Given the policy interest rate in the foreign country $i_{t}^{*}$, the domestic central bank maximizes welfare in the domestic country:

$$
\begin{aligned}
W_{t} & \equiv \mathbb{E}_{t} \sum_{T=t}^{\infty} \beta^{T-t}\left[\frac{C_{T}^{1-v}}{1-v}-\int_{0}^{1} l_{T}(h) \mathrm{d} h\right] \\
& =\mathbb{E}_{t} \sum_{T=t}^{\infty} \beta^{T-t}\left(\frac{Y_{T}^{1-v}}{1-v}-l_{T}\right),
\end{aligned}
$$

subject to equilibrium conditions in equations (16) to (26).

Similarly, the foreign central bank takes the policy interest in the domestic country $i_{t}$ as given and maximizes welfare in the foreign country:

$$
W_{t}^{*} \equiv \mathbb{E}_{t} \sum_{T=t}^{\infty} \beta^{T-t}\left(\frac{Y_{T}^{1-v}}{1-v}-l_{T}^{*}\right)
$$

subject to equilibrium conditions in equations (16) to (26).

Appendix B provides all equilibrium conditions involving Lagrange multipliers on the constraints in this problem under noncooperation. These determine the allocations under the optimal monetary policy in noncooperation.

\subsection{Ramsey Optimal Steady State}

The Ramsey optimal steady states are computed from equilibrium conditions by eliminating time subscripts. The aim of computing the Ramsey optimal steady states is 
twofold. First, we will derive the optimal monetary policy in the LQ framework following Benigno and Woodford (2005) and Benigno and Benigno (2006). This is because intuition for the optimal monetary policy can hardly be understood from the non-linear equilibrium conditions shown in Appendix B. LQ approximation must be conducted around the Ramsey optimal steady states. Second, the differences between cooperative and noncooperative regimes imply the existence of gains from policy cooperation in the long-run.

Appendix B shows the Ramsey optimal steady state for all variables under both cooperation (with subscript $C$ ) and noncooperation (with subscript $N$ ), where steady state markups are eliminated by subsidy. Here, only the Ramsey optimal steady states of endogenous variables except for auxiliary variables and the Lagrange multipliers are displayed. The Ramsey optimal steady states of policy interest rates, output, labor supply and loan interest rates under cooperation are as follows:

$$
\begin{gathered}
1+i_{C}=1+i_{C}^{*}=1 \\
Y_{C}=l_{C}=l_{C}^{*}=1
\end{gathered}
$$

and

$$
R_{C}=R_{C}^{*}=1
$$

Net interest rates are zero so the welfare costs stemming from the working capital loan becomes zero. This is considered the Friedman rule in the presence of the cost channel. Zero net nominal interest rates together with negative inflation rates become optimal in eliminating nominal distortions. Thus, the second distortion can be eliminated by the appropriate steady state conditions with negative inflation targeting. 
On the other hand, those under noncooperation are

$$
\begin{gathered}
1+i_{N}=1+i_{N}^{*}=1+v \\
Y_{N}=l_{N}=l_{N}^{*}=\left(\frac{1}{1+v}\right)^{\frac{1}{v}}
\end{gathered}
$$

and

$$
R_{N}=R_{N}^{*}=1+v
$$

Since the coefficient of the relative risk aversion, or, the inverse of the intertemporal elasticity of substitution, is positive $(v>0)$, both policy and loan interest rates are higher under the noncooperative regime $\left(i_{N}>i_{C}, R_{N}>R_{C}\right)$. Regarding output and labor supply, since

$$
\frac{d\left(\frac{1}{1+v}\right)^{\frac{1}{v}}}{d v}=\frac{d \exp \left[\frac{1}{v} \log \left(\frac{1}{1+v}\right)\right]}{d v}=\exp \left[\frac{1}{v} \log \left(\frac{1}{1+v}\right)\right]\left[\frac{1+v}{v}+\frac{\log (1+v)}{v^{2}}\right]>0
$$

whether or not it becomes larger under cooperation depends on the size of $v$. Appendix C proves that steady state welfare is indeed higher under cooperation. ${ }^{17}$

\subsection{Cooperation vs Noncooperation in the Long-Run}

The Ramsey optimal steady states under cooperation are different from those under noncooperation. In addition, steady state welfare is naturally higher under cooperation. Together these imply that there is welfare gain from cooperation in the long-run. Here, we aim to understand the sources of this long-run welfare gain.

In the absence of shocks and nominal (loan rate) rigidities, equilibrium conditions in

\footnotetext{
${ }^{17}$ The model involves endogenous state variables, namely $R_{t}$ and $R_{t}^{*}$. Thus, steady state welfare comparison may not be a good measure for evaluating the (policy) regimes. In particular, when the steady states for endogenous state variables are different, the steady states under the Pareto optimal allocation can be lower than those under alternative policy. For a detailed discussion on this point, see Bilbiie, Fujiwara, and Ghironi (2014).
} 
equations (16) to (26) collapse to the five equations below:

$$
\begin{gathered}
\frac{Y_{f, t}^{1-v}}{1+i_{f, t}}=l_{f, t}, \\
\frac{Y_{f, t}^{1-v}}{1+i_{f, t}^{*}}=l_{f, t}^{*}, \\
1=Y_{f, t}^{2 v}\left(1+i_{f, t}\right)\left(1+i_{f, t}^{*}\right), \\
R_{f, t}=1+i_{f, t},
\end{gathered}
$$

and

$$
R_{f, t}^{*}=1+i_{f, t}^{*},
$$

where the variables in this economy are denoted with subscript $f$. They can be also obtained by eliminating time subscripts in equilibrium conditions in equations (16) and (26). Thus, optimal policy analysis here can be considered to compute the golden rule allocation in the terminology of King and Wolman (1999).

The problem under cooperation is to maximize welfare defined in (32) subject to equations (37) to (39), while the domestic (foreign) central bank under the noncooperative regime aims to maximize welfare defined in (33) and (34) subject also to equations (37) to (39). The optimal allocations obtained from these problems are identical to the Ramsey optimal steady states, derived in the previous section. The differences in the Ramsey optimal steady states between cooperation and noncooperation can be understood from this simplified optimization problem for the golden rule allocations.

Equations (37) to (39) clarify the reason behind the differences. Equations (37) and (38) demonstrate that each central bank has an incentive to keep policy interest rates high to reduce the dis-utility stemming from labor supply. Corsetti and Pesenti (2001) call this incentive the deflationary bias. With the working capital loan and the complete financial market, the terms of trade $T o T_{t}$ can be expressed as the ratio of domestic over 
foreign loan rates: ${ }^{18}$

$$
T o T_{t}=\frac{S_{t} P_{H, t}^{*}}{P_{F, t}}=\frac{R_{t}}{R_{t}^{*}}
$$

Thus, each central bank aims to keep higher interest rates to improve the terms of trade.

On the other hand, equation (39), which is derived from the market clearing condition for final goods in equations (12) and (13) under the complete international financial market, shows that with globally lowered interest rates, both countries can enjoy more consumption and therefore higher welfare. Under the complete international financial market, it is not the policy interest rate in each individual country, but global interest rates, that is the arithmetic mean of interest rates of two countries, which determines global consumption and therefore consumption in each country. This becomes the source of the externality, which creates incentives for central banks to keep interest rates higher. Central banks under cooperation can internalize this externality. Consequently, interest rates under cooperation are lower than under noncooperation. Thus, there are gains in cooperation with the cost channel in the long-run. ${ }^{19}$

\section{Optimal Monetary Policy in LQ Framework}

The previous section clarifies that there are gains in cooperation in the long-run. In this section, we delve into whether gains exist even in the short-run, in particular, in optimal responses to structural shocks.

For this, we need to compare the optimal paths to shocks of all endogenous variables between cooperation and noncooperation using equilibrium conditions in Appendix B. ${ }^{20}$ Yet, there are too many equations, in particular, for auxiliary variables and co-state variables. Instead, in this section, we investigate the nature of the Ramsey optimal

\footnotetext{
${ }^{18}$ For the detailed derivation, see Appendix A, in particular, equations (89) to (92).

${ }^{19}$ Cooley and Quadrini (2003) explain the decline in interest rates after the advent of Euro were caused by monetary cooperation.

${ }^{20}$ Naturally, the same impulse responses are obtained under both non-linear and LQ Ramsey problems.
} 
policy using the LQ framework proposed by Benigno and Woodford (2005) and Benigno and Benigno (2006). ${ }^{21}$

\subsection{Loss Function under Cooperation}

First, welfare under cooperation in (32) is approximated up to the second order. We use the second order log approximation:

$$
\frac{X_{t}-X}{X} \approx \hat{x}_{t}+\frac{1}{2} \hat{x}_{t}^{2}
$$

Then, welfare under cooperation in (32) is approximated around the Ramsey optimal steady state as

$$
\begin{aligned}
W_{t}+W_{t}^{*} & \equiv \mathbb{E}_{t} \sum_{T=t}^{\infty} \beta^{T-t}\left(\frac{2 Y_{T}^{1-v}}{1-v}-l_{T}-l_{T}^{*}\right) \\
& \approx \mathbb{E}_{t} \sum_{t=0}^{\infty} \beta^{t}\left[2 \hat{Y}_{t}-\hat{l}_{t}-\hat{l}_{t}^{*}+(1-v) \hat{Y}_{t}^{2}-\frac{1}{2} \hat{l}_{t}^{2}-\frac{1}{2}\left(\hat{l}_{t}^{*}\right)^{2}\right] .
\end{aligned}
$$

Note that terms that are of the higher order than second order and independent from policy will not be shown hereafter.

By taking logs for equations (22) and (24), we have

$$
(1-v) \hat{Y}_{t}-\mu_{t}-\hat{R}_{t}+\hat{\Delta}_{t}=\hat{l}_{t}
$$

and

$$
(1-v) \hat{Y}_{t}-\hat{R}_{t}^{*}+\hat{\Delta}_{t}^{*}=\hat{l}_{t}^{*}
$$

\footnotetext{
${ }^{21}$ Benigno and Benigno (2006) is the application of Benigno and Woodford (2005) to a two country model. De Paoli (2009) derives the quadratic loss function in a small open economy using this technique.
} 
In addition, second order approximation to equations (23) and (25) leads to

$$
\mathbb{E}_{t} \sum_{t=0}^{\infty} \beta^{t} \Delta_{t} \approx \mathbb{E}_{t} \sum_{t=0}^{\infty} \beta^{t} \frac{\phi \sigma}{2(1-\phi)(1-\beta \phi)}\left(\hat{R}_{t}-\hat{R}_{t-1}\right)^{2}
$$

and

$$
\mathbb{E}_{t} \sum_{t=0}^{\infty} \beta^{t} \Delta_{t}^{*} \approx \mathbb{E}_{t} \sum_{t=0}^{\infty} \beta^{t} \frac{\phi \sigma}{2(1-\phi)(1-\beta \phi)}\left(\hat{R}_{t}^{*}-\hat{R}_{t-1}^{*}\right)^{2} .
$$

By substituting equations (42) to (45) into (41), the quadratic loss function under cooperation is derived:

$$
-\left(W_{t}+W_{t}^{*}\right) \equiv L_{t} \approx \mathbb{E}_{t} \sum_{t=0}^{\infty} \beta^{t}\left\{\begin{array}{c}
\frac{\phi \sigma}{(1-\phi)(1-\beta \phi)}\left(\hat{R}_{t}-\hat{R}_{t-1}\right)^{2}+\frac{\phi \sigma}{(1-\phi)(1-\beta \phi)}\left(\hat{R}_{t}^{*}-\hat{R}_{t-1}^{*}\right)^{2} \\
+\left(\hat{R}_{t}+\mu_{t}\right)^{2}+\left(\hat{R}_{t}^{*}\right)^{2} \\
+\frac{1-v}{2 v}\left[\left(\hat{R}_{t}+\mu_{t}\right)+\hat{R}_{t}^{*}\right]^{2}
\end{array}\right\} .
$$

The loss function in equation (46) shows that global welfare is represented by not only the loan inflation rate, namely the difference $\left(\hat{R}_{t}-\hat{R}_{t-1}\right)$, but also the level of loan interest rates $\hat{R}_{t}$. The former captures welfare costs stemming from relative loan rate dispersion in equations (14) and (29). The latter represents welfare losses from unsmoothed consumption. The cost channel controls the equilibrium dynamics in consumption and therefore, loan rates remain in the approximated loss function to represent welfare gain from consumption smoothing.

\subsection{Loss Functions under Noncooperation}

Under noncooperation, the loss functions for both domestic and foreign central banks are computed separately. The domestic welfare under noncooperation in (33) is approx- 
imated up to the second order as

$$
\begin{aligned}
W_{t} & \equiv \mathbb{E}_{t} \sum_{T=t}^{\infty} \beta^{T-t}\left(\frac{Y_{T}^{1-v}}{1-v}-l_{T}\right) \\
& \approx\left(\frac{1}{1+v}\right)^{\frac{1}{v}} \mathbb{E}_{t} \sum_{t=0}^{\infty} \beta^{t}\left[(1+v) \hat{Y}_{t}-\hat{l}_{t}+\frac{(1+v)(1-v)}{2} \hat{Y}_{t}^{2}-\frac{1}{2} \hat{l}_{t}^{2}\right] .
\end{aligned}
$$

After substituting equations (42) to (44) and ignoring the parameters before the summation, this collapses to

$$
-\mathbb{E}_{t} \sum_{t=0}^{\infty} \beta^{t}\left\{\begin{array}{c}
\hat{R}_{t}^{*}+\frac{\phi \sigma}{2(1-\phi)(1-\beta \phi)}\left(\hat{R}_{t}-\hat{R}_{t-1}\right)^{2} \\
-\frac{1-v}{4 v}\left[\left(\hat{R}_{t}^{*}-z_{t}\right)^{2}+\left(\hat{R}_{t}+\mu_{t}\right)^{2}\right]+\frac{1}{2}\left(\hat{R}_{t}+\mu_{t}\right)^{2}
\end{array}\right\}
$$

Contrary to the loss function under cooperation in (46), the linear term $\hat{R}_{t}^{*}$ still remains. $\hat{R}_{t}^{*}$ represents the terms of trade externality. The domestic central bank prefers $\hat{R}_{t}^{*}$ to be lower since this reduces social loss in (48). This is because lower $\hat{R}_{t}^{*}$ improves the terms of trade for the domestic country as shown in equation (40).

A linear term in the welfare metric will result in a spurious welfare evaluation in the LQ framework. ${ }^{22}$ Here, following Benigno and Woodford (2005) and Benigno and Benigno (2006), we take the second order approximation to equilibrium conditions and obtain the approximated equations where linear terms are expressed only by quadratic terms. By using such second orderly approximated equilibrium conditions, we can substitute out linear terms in the welfare metric with quadratic terms.

Appendix D shows further detail of how to derive the quadratic approximation of the loan rate Phillips curves in equations (16) to (18) or (19) to (21). From the second order approximation of the loan rate Phillips curve in the foreign country in equations (19) to

\footnotetext{
${ }^{22}$ For details on this, see, for example, Sutherland (2002), Kim and Kim (2003, 2007), Benigno and Woodford (2005, 2012) and Kim, Kim, Schaumburg, and Sims (2008).
} 
(21), we can derive

$$
\mathbb{E}_{t} \sum_{t=0}^{\infty} \beta^{t}\left(i_{t}^{*}-\hat{R}_{t}^{*}\right) \approx \mathbb{E}_{t} \sum_{t=0}^{\infty} \beta^{t}\left[\begin{array}{c}
-(1-v) \hat{Y}_{t}\left(i_{t}^{*}-\hat{R}_{t}^{*}\right)-\frac{1}{2}\left(i_{t}^{*}-\hat{R}_{t}^{*}\right)^{2} \\
-\frac{\sigma \phi}{2(1-\beta \phi)(1-\phi)}\left(\hat{R}_{t}^{*}-\hat{R}_{t-1}^{*}\right)^{2}
\end{array}\right]
$$

By substituting this approximated relationship in (49) into the approximated welfare measure in (48), we can derive the quadratic loss function which the domestic central bank aims to minimize:

$$
L_{t}^{D} \approx \mathbb{E}_{t} \sum_{t=0}^{\infty} \beta^{t}\left\{\begin{array}{c}
\frac{\sigma \phi}{(1-\beta \phi)(1-\phi)}\left(\hat{R}_{t}-\hat{R}_{t-1}\right)^{2}+\frac{\phi \sigma}{(1-\phi)(1-\beta \phi)}\left(\hat{R}_{t}^{*}-\hat{R}_{t-1}^{*}\right)^{2} \\
+\left(\hat{R}_{t}+\mu_{t}\right)^{2}+\left(\hat{R}_{t}^{*}-i_{t}^{*}\right)^{2} \\
+\frac{1-v}{2 v}\left[\left(\hat{R}_{t}+\mu_{t}\right)+\left(\hat{R}_{t}^{*}-i_{t}^{*}\right)\right]^{2}
\end{array}\right\}
$$

Similarly, from the second order approximation of the loan rate Phillips curve in the domestic country in equations (16) to (18), we can obtain

$$
\mathbb{E}_{t} \sum_{t=0}^{\infty} \beta^{t}\left(i_{t}-\hat{R}_{t}+u_{t}+\mu_{t}\right) \approx \mathbb{E}_{t} \sum_{t=0}^{\infty} \beta^{t}\left\{\begin{array}{c}
-\left[z_{t}+(1-v) \hat{Y}_{t}\right]\left(i_{t}+\mu_{t}+u_{t}-\hat{R}_{t}\right) \\
-\frac{1}{2}\left(i_{t}+u_{t}+\mu_{t}-\hat{R}_{t}\right)^{2} \\
-\frac{\sigma \phi}{2(1-\beta \phi)(1-\phi)}\left(\hat{R}_{t}-\hat{R}_{t-1}\right)^{2}
\end{array}\right\} .
$$

By using this approximated relationship in (51), we can derive the quadratic loss function for the foreign central bank as

$$
L_{t}^{F} \approx \mathbb{E}_{t} \sum_{t=0}^{\infty} \beta^{t}\left\{\begin{array}{c}
\frac{\sigma \phi}{(1-\beta \phi)(1-\phi)}\left(\hat{R}_{t}-\hat{R}_{t-1}\right)^{2}+\frac{\phi \sigma}{(1-\phi)(1-\beta \phi)}\left(\hat{R}_{t}^{*}-\hat{R}_{t-1}^{*}\right)^{2} \\
+\left[\hat{R}_{t}-\left(i_{t}+\mu_{t}+u_{t}\right)\right]^{2}+\left(\hat{R}_{t}^{*}\right)^{2} \\
+\frac{1-v}{2 v}\left\{\left[\hat{R}_{t}-\left(i_{t}+\mu_{t}+u_{t}\right)\right]+\hat{R}_{t}^{*}\right\}^{2}
\end{array}\right\}
$$




\subsection{Cooperation vs Noncooperation in the Short-Run}

We first define the optimal allocations in the LQ framework as follows. ${ }^{23}$

Definition 1 The optimal cooperative allocation is the sequence of endogenous variables $\left\{\hat{R}_{t}, \hat{R}_{t}^{*}, i_{t}, i_{t}^{*}, \hat{Y}_{t}\right\}$ that minimizes (46) under the constraints (27), (28), and (30), given the sequence of shocks $\left\{u_{t}, z_{t}, \mu_{t}\right\}$ and the initial conditions: $\hat{R}_{0}$ and $\hat{R}_{0}^{*}$.

Definition 2 The optimal noncooperative allocation is the sequence of endogenous variables $\left\{\hat{R}_{t}, \hat{R}_{t}^{*}, i_{t}, i_{t}^{*}, \hat{Y}_{t}\right\}$, that minimizes (50) under the constraints (27), (28), and (30), given the sequence of the foreign policy interest rate $i_{t}^{*}$, shocks $\left\{u_{t}, \mu_{t}, z_{t}\right\}$ and the initial conditions: $\hat{R}_{0}$ and $\hat{R}_{0}^{*}$, and that minimizes (52) under the constraints (27), (28), and (30), given the sequence of the domestic policy interest rate $i_{t}$, shocks $\left\{u_{t}, z_{t}, \mu_{t}\right\}$ and the initial conditions: $\hat{R}_{0}$ and $\hat{R}_{0}^{*}$.

Note that parameters in equations (27), (28) and (30) do not rely on steady state values. Also, regarding the loss functions in (46), (50) and (52), the difference in steady states only matters for the parameters before the summation as in (47), which can be ignored when computing the optimal monetary policy. Therefore, even though the Ramsey steady states are different between cooperation and noncooperation, optimal responses are not affected by this difference.

Below, we describe how the optimal monetary policy under both cooperation and noncooperation will react to the technology shock, the loan premium shock and the markup shock, respectively.

\subsubsection{Technology Shock}

Note that the technology shock $z_{t}$ is not included in the loss functions under both cooperation and noncooperation, as shown in equations (46), (50) and (52). This fact implies

\footnotetext{
${ }^{23} \hat{Y}_{t}$ is passively determined via equation (30). Thus, it can be excluded from the determination of optimal monetary policy.
} 
that the level of loan rates or loan inflation rates, that the central banks aim to achieve, are independent from the technology shock.

In a standard new Keynesian model, due to sticky prices, the technology shock alters the natural rate, namely output under the flexible price equilibrium. Therefore, the output gap, which is defined as the difference in output between the sticky and flexible price equilibria and thus the central banks aim to minimize, also shifts as the technology shock changes. In contrast, in our model, due to the flexibility in price settings, the technology shock does not change the output gap. Thus, for the central bank, it is optimal to stabilize fluctuations in loan rates determined by equations (27) and (28). These equations do not contain the technology shock as a component of marginal costs for supplying loans.

Under both cooperation and noncooperation, it is optimal to completely stabilize the fluctuations in loan rates in both domestic and foreign countries. Any fluctuations in output $\hat{Y}_{t}$ according to equation (30) under $\hat{R}_{t}=\hat{R}_{t}^{*}=0$, namely,

$$
\hat{Y}_{t}=\frac{1}{2 v} z_{t}
$$

are optimal and should not be corrected by policy actions. Thus, there is no additional gain from cooperation.

\subsubsection{Loan Premium Shock}

Contrary to the technology shock, the loan premium shock is included in the loss function in the foreign country as in equation (52) as well as in the domestic loan rate Phillips curve in equation (27). Despite this, the loan premium shock does not require policy cooperation either.

Under cooperation, since the loan premium shock is not included in the global loss function in equation (46), central banks in both countries should aim to achieve complete 
loan rate stability as $\hat{R}_{t}=\hat{R}_{t}^{*}=0$. This can be achieved by setting the domestic policy interest rate to eliminate the domestic loan premium shock in the domestic loan Phillips curve in equation (27) such that $i_{t}=-u_{t}$.

Under noncooperation, the domestic central bank aims to completely stabilize loan rates since the loss function does not contain the loan premium shock. To achieve this, again, the domestic policy rate is set to eliminate the loan premium shock. By doing so, loan rates are completely stabilized, since the marginal costs of supplying domestic loans in equation (27) are not fluctuating. Although the loan premium shock is included in the foreign loss function in equation (52), the domestic policy interest rate is not controllable by the foreign central bank. Consequently, the complete stabilization of loan rates by the domestic central bank suffices to achieve the optimal allocations. Again, there is no gain from cooperation.

\subsubsection{Markup Shock}

The markup shock is reported to be an important driver of the business cycles in many studies with the prototypical DSGE model following Christiano, Eichenbaum, and Evans (2005) and Smets and Wouters (2003, 2007). Bayesian maximum likelihood estimation of the DSGE model of the Euro area by Gerali, Neri, Sessa, and Signoretti (2010) provides sizable estimates of standard errors in the banking sector markup shocks. Also, the authors report significant contributions from markup shocks in the banking sector in the fluctuations of financial (and therefore real economic) variables between 2004 and 2009 including the peak of the recent global financial crisis.

The optimal responses to the markup shock $\mu_{t}$ under both cooperation and noncooperation are shown in Figures 2 and 3. The markup shock follows an AR(1) process with a parameter of 0.9. Responses to shocks are derived under commitment together with the assumption that the initial endogenous state variables are set at their optimal steady 
Figure 2: Optimal Responses to Markup Shock: $v=2$
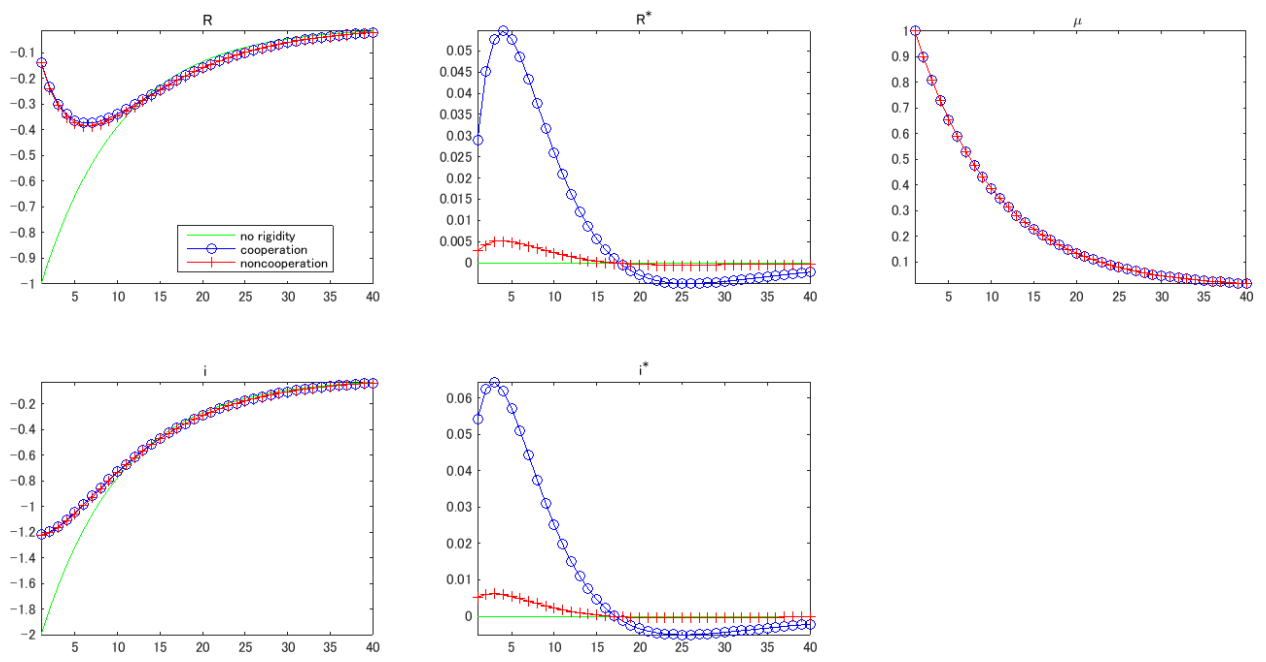

state values. ${ }^{24}$ The parameters in Table 1 are again employed, but for the coefficient of the relative risk aversion $v$, we examine two values; Figures 2 and 3 show those when $v=2$, and $v=0.5$, respectively.

Terms of Trade vs Risk Sharing As equation (18) implies, this is a shock to reduce the markup. With sticky loan rates, as implicit in equations (22) and (24), and explicit in loss functions in (46), (50) and (52), fluctuations in loan interest rates results in resource costs. Consequently, under both cooperation (blue lines) and noncooperation (red lines), in order to avoid resource costs stemming from loan rate dispersion, loan interest rates gradually change after a negative markup shock.

When $v=2$, foreign loan and policy interest rates move in the opposite direction to domestic interest rates. On the other hand, when $v=0.5$, they both move in the same direction. In this model, since the intra-temporal elasticity of substitution between domestic and foreign goods is set at unity as in equation (7), the coefficient of relative risk aversion solely determines whether goods produced in the two countries are Edgeworth

\footnotetext{
${ }^{24}$ This is the timeless optimal monetary policy in the terminology of King and Wolman (1999).
} 
Figure 3: Optimal Responses to Markup Shock: $v=0.5$
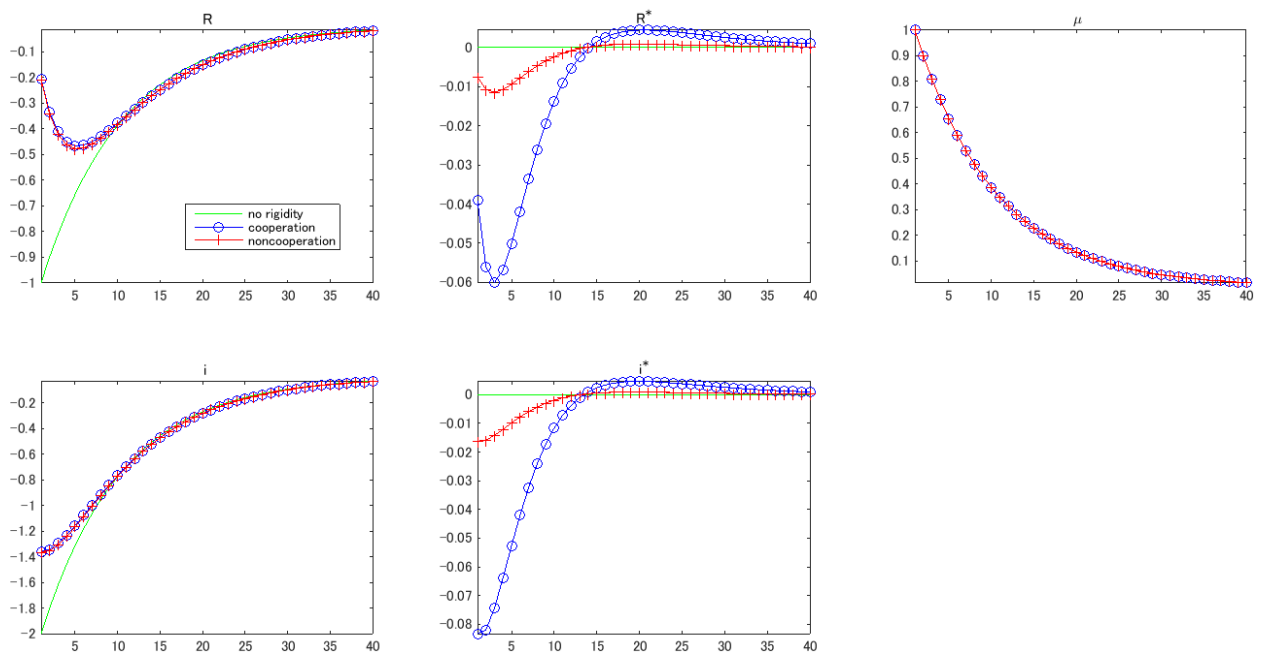

complements or substitutes. ${ }^{25}$ When $v>1(v<1)$, for instance, the intertemporal elasticity of substitution becomes lower (higher) than the intra-temporal elasticity of substitution. In this situation, home goods and foreign goods are Edgeworth substitutes (complements). Consequently, output in the domestic country moves in the opposite (same) direction to that of the foreign country.

This mechanism can be understood by analyzing the relationship between marginal costs and the terms of trade. By combining the resource constraint with the labor market equilibrium condition, only marginal costs with the presence of the markup shock are given by

$$
M C_{t}=\frac{w_{t}}{P_{H, t}}=\left(\frac{l_{t}}{\Delta_{t}}\right)^{v} \operatorname{ToT}_{t}^{\psi(v-1)},
$$

where $\psi$ is $0.5 .{ }^{26}$ Improvements of the terms of trade have two opposing effects to marginal costs. First, by affecting output prices, improvements in the terms of trade directly

\footnotetext{
${ }^{25}$ For more detail on this point, see, for example, Tille (2001), Clarida, Gali, and Gertler (2002), Benigno and Benigno (2003, 2006), Fujiwara, Nakajima, Sudo, and Teranishi (2013) and Fujiwara and Ueda (2013). When $v=1$, namely with the log utility, two countries become insular and thre is no spillover between the two countries.

${ }^{26}$ Equations (59), (66), (71) and (85) in Appendix A are used.
} 
decrease marginal costs in the home country. Second, these result in production switching from domestically-produced to foreign-produced goods. Given domestic output, this requires a rise in output in the foreign country. Total consumption rises in both countries, and due to risk sharing, both domestic and foreign consumption rise by the same amount. A rise in domestic consumption raises marginal costs in the home country, and to offset the rise in prices, home employment must decrease. In the terminology of Clarida, Gali, and Gertler (2002), the former is the terms of trade effect while the latter is the risk sharing effect. For example, when $v>1$, the latter dominates the former channel. A negative shock to the markup in the domestic country reduces domestic loan interest rates. As shown in equation (40), this worsens the terms of trade for the domestic country and therefore improves the foreign terms of trade. The negative markup shock spills over to the foreign country as if it were a positive shock to marginal costs. Consequently, in this case, foreign loan rates should increase.

Flexible Loan Rates Green lines represent the optimal responses when there are no rigidities in loan rate settings. Under flexible loan rates, the first two terms in the loss functions in (46), (50) and (52) disappear. Since no welfare cost stems from the fluctuations in loan inflation rates $\left(\hat{R}_{t}-\hat{R}_{t-1}\right)$, there exists no trade-off between stabilizing the difference or the level of loan rates. Thus, central banks under both cooperation and noncooperation can solely concentrate on stabilizing output fluctuations, which are captured by the third to the fifth terms in (46), (50) and (52). Note that changes in the level of loan rates can lead to inefficient fluctuations in output and therefore consumption eventually, under the working capital loan. ${ }^{27}$

When loan rates are flexible, namely $\phi=0$, loan rate Phillips curves in equations

\footnotetext{
${ }^{27}$ When prices are flexible, no role is left for monetary policy in the standard new Keynesian model. In contrast, in our model, the central bank can still improve social welfare even with flexible loan rates. The price level does not matter under flexible prices in the standard model, but the level of the loan rates matters under the working capital loan.
} 
(27) and (28) collapse to

$$
\hat{R}_{f, t}=i_{f, t}+\mu_{t}
$$

and

$$
\hat{R}_{f, t}^{*}=i_{f, t}^{*}
$$

Whether central banks are under cooperation or noncooperation, by controlling $i_{f, t}$ and $i_{f, t}$, central banks can set loan interest rates to eliminate inefficient fluctuations stemming from the markup shock, that are represented by the third to the fifth terms in (46), (50) and (52). The optimal dynamics without loan rate stickiness under both cooperation and noncooperation are derived as follows:

$$
\begin{gathered}
\hat{R}_{f, t}=-\mu_{t}, \\
\hat{R}_{f, t}^{*}=0, \\
i_{f, t}=-2 \mu_{t}, \\
i_{f, t}^{*}=0,
\end{gathered}
$$

and

$$
\hat{Y}_{f, t}=0
$$

When a negative shock is applied to the domestic markup, equation (54) implies that in the absence of staggered loan contracts, domestic loan rates should be decreased immediately. There is no difference in the optimal responses under flexible loan settings between cooperation and noncooperation. Although steady states are different, central banks under both cooperation and noncooperation have the same goal for their stabilization policies to structural shocks. The markup shock changes the target level of loan interest rates differently between two countries under noncooperation, but monetary pol- 
icy can completely eliminate social loss defined in (46), (50) and (52) stemming from the mark up shock by achieving equation (54).

Gains from Cooperation When loan rates are revised infrequently, significant differences between cooperation (blue lines) and noncooperation (red lines) are observed in the responses of foreign loan and policy interest rates. This is because under noncooperation, central banks in both countries are unable to internalize the terms of trade externality as discussed above and in such papers as Corsetti and Pesenti (2001) and Benigno and Benigno (2006). The domestic (foreign) central bank aims to reduce $R_{t}^{*}\left(R_{t}\right)$ to minimize social loss in (48) in order to improve the terms of trade in equation (40). Consequently, against a positive markup shock, as evident in the domestic loss function (50), the domestic central bank wants to have lower domestic loan rates $\left(\hat{R}_{t}=-\mu_{t}\right)$ against a positive markup shock, while as the foreign loss function (52) shows, the foreign central bank tries to maintain domestic loan rates to be higher $\left(\hat{R}_{t}=i_{t}+\mu_{t}\right)$.

This incentive to manipulate the terms of trade is absent without loan stickiness. When loan rates are flexible, there is no need for the domestic (foreign) central bank to influence foreign (domestic) loan rates. Monetary policy can completely eliminate social loss stemming from the markup shock. On the other hand, when loan rates are sticky, the foreign (domestic) loan rate Phillips curve becomes a binding constraint for the domestic (foreign) central bank. Thus, the domestic (foreign) central bank has an incentive to control foreign (domestic) loan rates to improve the terms of trade for the domestic (foreign) country. Achieving equation (54) is not optimal any more, since this creates dispersion in loan rates. Room emerges for the domestic (foreign) central bank to manipulate loan rates in the foreign (domestic) country.

Through the relationship of domestic marginal costs and the terms of trade in equation (53), when $v>1(v<1)$, increases (decreases) in policy interest rates in the foreign country alleviate the problem of the domestic country stemming from a shock to reduce 
the markup. Foreign monetary policy under noncooperation only reacts to the spillover effects on foreign marginal costs from the markup shock in the domestic country. As a result, under noncooperation, the reactions of foreign variables to the domestic markup shock are lessened.

\section{International Banking}

So far, we have omitted international lending and borrowing. Financial globalization has been expanding quite rapidly. We can easily observe this trend from recent financial and economic developments. Gadanecz (2004), McGuire and Tarashev (2006), and Lane and Milesi-Ferretti (2007, 2008) formally show that more funds from foreign countries are flowing into the domestic financial markets of other countries. In this subsection, we extend our model to incorporate international lending and borrowing. Two cases will be examined, namely, international funding and international lending and borrowing.

\subsection{International Funding}

As equation (11) implies, domestic private banks borrow solely from the domestic financial market. Assume instead that private bank $h$ can now borrow a portion $\alpha$ from the domestic financial market as well as a portion $1-\alpha$ from the foreign financial market. Then, the profit defined in equation (11) can be re-written as

$$
\Pi_{t}^{B}(h)=q_{t}(h)\left[\left(1+\tau_{t}\right) R_{t}(h)-\alpha\left(1+i_{t}\right)-(1-\alpha) \mathbb{E}_{t} \frac{S_{t+1}}{S_{t}}\left(1+i_{t}^{*}\right)\right]
$$

The complete international financial market implies the UIP (uncovered interest rate parity) condition:

$$
1+i_{t}=\mathbb{E}_{t} \frac{S_{t+1}}{S_{t}}\left(1+i_{t}^{*}\right) \exp \left(\varepsilon_{t}\right)
$$

where we add the so-called UIP shock $\varepsilon_{t}$, the importance of which has been emphasized by 
many empirical studies on international macroeconomics, such as Lubik and Schorfheide (2006). By combining equations (55) and (56), we have the modified profit equation under international lending and borrowing:

$$
\Pi_{t}^{B}(h)=q_{t}(h)\left\{\left(1+\tau_{t}\right) R_{t}(h)-\left(1+i_{t}\right)\left[\alpha+\frac{1-\alpha}{\exp \left(\varepsilon_{t}\right)}\right]\right\} .
$$

Our results so far will not change even when private banks can borrow internationally. Furthermore, the UIP shock works similarly to the loan premium shock.

\subsection{International Lending and Borrowing}

Next, let us consider the situation where firms can borrow internationally. Suppose that domestic firms borrow a portion $\alpha$ from the domestic private bank as well as a portion $1-\alpha$ from the foreign private bank. ${ }^{28}$ Then, the profit equation of the domestic firm $h$ in equation (6) is re-written as

$$
\begin{aligned}
\Pi_{t}^{F}(h)= & \left(1+\tau_{t}\right)\left[p_{t}(h) y_{t}(h)+S_{t} p_{t}^{*}(h) y_{t}^{*}(h)\right] \\
& -\alpha R_{t}(h) w_{t}(h) l(h) \\
& -(1-\alpha) \mathbb{E}_{t} \frac{S_{t+1}}{S_{t}} R_{t}^{*}(h) w_{t}(h) l_{t}(h)
\end{aligned}
$$

The second terms can be transformed into

$$
\alpha R_{t}(h) w_{t}(h) l(h)=\alpha M U_{t}^{R}(h)\left(1+i_{t}\right) w_{t}(h) l(h) \exp \left(u_{t}\right)
$$

while, by using equation (56), the third term can be written as

$$
(1-\alpha) \mathbb{E}_{t} \frac{S_{t+1}}{S_{t}} R_{t}^{*}(h) w_{t}(h) l_{t}(h)=(1-\alpha) M U_{t}^{R^{*}}(h)\left(1+i_{t}\right) w_{t}(h) l_{t}(h) \exp \left(\varepsilon_{t}\right) .
$$

\footnotetext{
${ }^{28}$ For detailed analysis on this issue, see our working version of this paper: Fujiwara and Teranishi (2009).
} 
$M U_{t}^{R}(h)$ and $M U_{t}^{R^{*}}(h)$ are time-varying markups for lending rates to domestic firm $h$ stemming from monopolistic competition and staggered loan contracts. As long as the UIP holds and the foreign bank lends to domestic firms in the foreign currency unit, the funding rate turns out to be the same as the domestic saving rate irrespective of the existence of international or domestic lending. International lending and borrowing do not alter the nature of the optimal monetary policy under both cooperation and noncooperation discussed in this paper. ${ }^{29}$

\section{Conclusion}

We show that policy cooperation increases social welfare in a model with simple financial frictions with monopolistic banking and staggered loan contracts in a tractable framework.

In order to understand the implications of financial frictions for policy cooperation, we employ a simple financial system consisting only of cost channel, monopoly power by banks and staggered loan contracts. Recently, there have been many attempts to positively analyze the role of financial frictions with more detailed modeling of financial sectors, following such studies as Kiyotaki and Moore (1997), Bernanke, Gertler, and

\footnotetext{
${ }^{29}$ The working paper version of this paper: Fujiwara and Teranishi (2009) also considers international lending for domestic firms in the domestic currency. There, for example, the profit equation of the domestic firm $h$ can be written as

$$
\Pi_{t}^{F}(h)=(1+\tau)\left[p_{t}(h) y_{t}(h)+S_{t} p_{t}^{*}(h) y_{t}^{*}(h)\right]-\left[\omega \mathbb{E}_{t} \frac{S_{t+1}}{S_{t}}+(1-\omega)\right] R_{t}^{*}(h) w_{t}(h) l_{t}(h) .
$$

while that foreign bank $h$ is

$$
\Pi_{t}^{B^{*}}(h)=q_{t}(h)\left\{(1+\tau)\left[\omega+(1-\omega) \mathbb{E}_{t} \frac{S_{t+1}}{S_{t}}\right] R_{t}^{*}(h)-i_{t}^{*}\right\} .
$$

The parameter $\omega$ determines how much is borrowed in the foreign currency unit. For example, if $\omega=1$, the domestic firm borrows in the foreign currency unit and therefore incurs all exchange rate risks.

Under this setting, the central bank under noncooperation has an additional incentive to appreciate domestic currency in order to reduce loan payments. Consequently, differences arise in the optimal allocations and prices between cooperative and non-cooperative regimes even with other shocks than the markup shock.
} 
Gilchrist (1999), Gertler and Kiyotaki (2010), or Gertler and Karadi (2011). Optimal monetary policy analysis together with a complex banking sector becomes increasingly difficult with the existence of the endogenous state variables. ${ }^{30}$ Will this extension drastically change our main results? This issue is left for future research.

\footnotetext{
${ }^{30}$ Bodenstein, Guerrieri, and LaBriola (2014) report numerical results on optimal monetary policy analysis with financial frictions based on Gertler and Karadi (2011).

Analysis with the LQ framework becomes complicated with the endogenous state variables. See, for example, Edge (2003).
} 


\section{References}

Andrés, J., And O. J. Arce (2012): "Banking Competition, Housing Prices and Macroeconomic Stability," Economic Journal, 122(565), 1346-1372.

Barth, M. J., And V. A. Ramey (2002): "The Cost Channel of Monetary Transmission," in NBER Macroeconomics Annual 2001, Volume 16, NBER Chapters, pp. 199-256. National Bureau of Economic Research, Inc.

Benigno, G., And P. Benigno (2003): "Price Stability in Open Economies," Review of Economic Studies, 70(4), 743-764.

(2006): "Designing targeting rules for international monetary policy cooperation," Journal of Monetary Economics, 53(3), 473-506.

Benigno, P., And M. Woodford (2005): "Inflation Stabilization and Welfare: The Case of a Distorted Steady State," Journal of the European Economic Association, $3(6), 1185-1236$.

_ (2012): "Linear-quadratic approximation of optimal policy problems," Journal of Economic Theory, 147(1), 1-42.

Berger, A. N., and G. F. Udell (1992): "Some Evidence on the Empirical Significance of Credit Rationing," Journal of Political Economy, 100(5), 1047-77.

Bernanke, B. S., M. Gertler, and S. Gilchrist (1999): "The Financial Accelerator in a Quantitative Business Cycle Framework," in Handbook of Macroeconomics, ed. by J. B. Taylor, and M. Woodford, vol. 1 of Handbook of Macroeconomics, chap. 21, pp. 1341-1393. Elsevier.

Bilbite, F. O., I. Fujiwara, and F. Ghironi (2014): "Optimal monetary policy with endogenous entry and product variety," Journal of Monetary Economics, 64(C), 1-20. 
Bodenstein, M., L. Guerrieri, and J. LaBriola (2014): "Macroeconomic Policy Games," Finance and Economics Discussion Series 2014-87, Board of Governors of the Federal Reserve System (U.S.).

Calem, P. S., M. B. Gordy, and L. J. Mester (2006): "Switching costs and adverse selection in the market for credit cards: New evidence," Journal of Banking $\mathcal{E} 3$ Finance, 30(6), 1653-1685.

Calvo, G. A. (1983): "Staggered Prices in A Utility-Maximizing Framework," Journal of Monetary Economics, 12(3), 383-398.

Christiano, L. J., M. Eichenbaum, and C. L. Evans (1999): "Monetary Policy Shocks: What Have We Learned and to What End?," in Handbook of Macroeconomics, ed. by J. B. Taylor, and M. Woodford, vol. 1 of Handbook of Macroeconomics, chap. 21, pp. 65-148. Elsevier.

(2005): "Nominal Rigidities and the Dynamic Effects of a Shock to Monetary Policy," Journal of Political Economy, 113(1), 1-45.

Clarida, R., J. Gali, and M. Gertler (2002): "A Simple Framework for International Monetary Policy Analysis," Journal of Monetary Economics, 49(5), 879-904.

Cooley, T. F., and V. Quadrini (2003): "Common Currencies vs. Monetary Independence," Review of Economic Studies, 70(4), 785-806.

Corsetti, G., L. Dedola, and S. Leduc (2010): "Optimal Monetary Policy in Open Economies," in Handbook of Monetary Economics, ed. by B. M. Friedman, and M. Woodford, vol. 3 of Handbook of Monetary Economics, chap. 16, pp. 861-933. Elsevier.

Corsetti, G., and P. Pesenti (2001): "Welfare And Macroeconomic Interdependence," The Quarterly Journal of Economics, 116(2), 421-445. 
De PAoli, B. (2009): “Monetary Policy and Welfare in a Small Open Economy," Journal of International Economics, 77(1), 11-22.

Edge, R. M. (2003): "A Utility-Based Welfare Criterion in a Model with Endogenous Capital Accumulation," Finance and Economics Discussion Series 2003-66, Board of Governors of the Federal Reserve System (U.S.).

Fujiwara, I., T. Nakajima, N. Sudo, and Y. Teranishi (2013): "Global Liqudity Trap," Journal of Monetary Economics, 60(8).

Fujiwara, I., And Y. Teranishi (2009): "Financial Stability in Open Economies," IMES Discussion Paper Series 09-E-09, Institute for Monetary and Economic Studies, Bank of Japan.

(2011): "Real exchange rate dynamics revisited: A case with financial market imperfections," Journal of International Money and Finance, 30(7), 1562-1589.

FujiWARA, I., AND K. UEDA (2013): "The fiscal multiplier and spillover in a global liquidity trap," Journal of Economic Dynamics and Control, 37(7), 1264-1283.

Gadanecz, B. (2004): "The Syndicated Loan Market," BIS Quarterly Review.

Gambacorta, L. (2008): "How do banks set interest rates?," European Economic Review, 52(5), 792-819.

Gerali, A., S. Neri, L. Sessa, and F. M. Signoretti (2010): "Credit and Banking in a DSGE Model of the Euro Area," Journal of Money, Credit and Banking, 42(s1), $107-141$.

Gertler, M., And P. Karadi (2011): "A model of unconventional monetary policy," Journal of Monetary Economics, 58(1), 17-34. 
Gertler, M., and N. Kiyotaki (2010): "Financial Intermediation and Credit Policy in Business Cycle Analysis," in Handbook of Monetary Economics, ed. by B. M. Friedman, and M. Woodford, vol. 3 of Handbook of Monetary Economics, chap. 11, pp. 547-599. Elsevier.

Giannoni, M. P. (2014): "Optimal interest-rate rules and inflation stabilization versus price-level stabilization," Journal of Economic Dynamics and Control, 41(C), 110-129.

Graham, L., and S. Wright (2007): "Nominal Debt Dynamics, Credit Constraints and Monetary Policy," The B.E. Journals of Macroeconomics, 7(1).

Gropp, R., And A. K. Kashyap (2010): "A New Metric for Banking Integration in Europe," in Europe and the Euro, NBER Chapters, pp. 219-246. National Bureau of Economic Research, Inc.

Hannan, T. H., And A. N. Berger (1991): "The Rigidity of Prices: Evidence from the Banking Industry," American Economic Review, 81(4), 938-45.

Kim, J., S. Kim, E. Schaumburg, and C. A. Sims (2008): "Calculating and using second-order accurate solutions of discrete time dynamic equilibrium models," Journal of Economic Dynamics and Control, 32(11), 3397-3414.

Kim, J., AND S. H. Kim (2003): "Spurious welfare reversals in international business cycle models," Journal of International Economics, 60(2), 471-500.

- (2007): "Two Pitfalls of Linearization Methods," Journal of Money, Credit and Banking, 39(4), 995-1001.

King, R., And A. L. Wolman (1999): "What Should the Monetary Authority Do When Prices Are Sticky?," in Monetary Policy Rules, NBER Chapters, pp. 349-404. National Bureau of Economic Research, Inc. 
Kiyotaki, N., and J. Moore (1997): "Credit Cycles," Journal of Political Economy, 105(2), 211-45.

Kobayashi, T. (2008): "Incomplete Interest Rate Pass-Through and Optimal Monetary Policy," International Journal of Central Banking, 4(3), 77-118.

Lane, P. R., and G. M. Milesi-Ferretti (2007): "The External Wealth of National Mark II," Journal of International Economics, 73(2), 223-50.

— (2008): "The Drivers of Financial Globalization," American Economic Review, 98(2), 327-32.

Lubik, T., And F. Schorfheide (2006): "A Bayesian Look at the New Open Economy Macroeconomics," in NBER Macroeconomics Annual 2005, Volume 20, NBER Chapters, pp. 313-382. National Bureau of Economic Research, Inc.

Mandelman, F. S. (2010): "Business cycles and monetary regimes in emerging economies: A role for a monopolistic banking sector," Journal of International Economics, 81(1), 122-138.

_ (2011): "Business Cycles and the Role of Imperfect Competition in the Banking System," International Finance, 14(1), 103-133.

McGuire, P., and N. Tarashev (2006): "Tracking International Bank Flows," BIS Quarterly Review, 27(4).

Perri, F., and V. Quadrini (2011): "International Recessions," NBER Working Papers 17201, National Bureau of Economic Research, Inc.

Ravenna, F., and C. E. Walsh (2006): "Optimal monetary policy with the cost channel," Journal of Monetary Economics, 53(2), 199-216. 
Slovin, M. B., And M. E. Sushka (1983): "A Model of the Commercial Loan Rate," Journal of Finance, 38(5), 1583-96.

Smets, F., And R. Wouters (2003): "An Estimated Dynamic Stochastic General Equilibrium Model of the Euro Area," Journal of the European Economic Association, $1(5), 1123-1175$.

Smets, F., And R. Wouters (2007): "Shocks and Frictions in US Business Cycles: A Bayesian DSGE Approach," American Economic Review, 97(3), 586-606.

Sorensen, C. K., And T. Werner (2006): "Bank Interest Rate Pass-Through in the Euro Area: A Cross Country Comparison," Working Paper Series 580, European Central Bank.

Steinsson, J. (2008): "The Dynamic Behavior of the Real Exchange Rate in Sticky Price Models," American Economic Review, 98(1), 519-33.

Sutherland, A. (2002): "A Simple Second-Order Solution Method for Dynamic General Equilibrium Models," Discussion Paper Series, Department of Economics 200211, Department of Economics, University of St. Andrews.

Teranishi, Y. (2015): "Smoothed Interest Rate Setting by Central Banks and Staggered Loan Contracts," Economic Journal, 125(582), 162-183.

Tille, C. (2001): "The Role of Consumption Substitutability in the International Transmission of Monetary Shocks," Journal of International Economics, 53(2), 421-444.

van Leuvensteijn, M., C. K. Sorensen, J. A. Bikker, and A. A. van Rixtel (2013): "Impact of bank competition on the interest rate pass-through in the euro area," Applied Economics, 45(11), 1359-1380.

Woodford, M. (2003): Interest and Prices: Foundations of a Theory of Monetary Policy. Princeton University Press, Princeton. 
Yun, T. (1996): "Nominal Price Rigidity, Money Supply Endogeneity, and Business Cycles," Journal of Monetary Economics, 37(2-3), 345-370.

(2005): "Optimal Monetary Policy with Relative Price Distortions," American Economic Review, 95(1), 89-109. 


\section{Appendix A: Equilibrium Conditions}

\section{Consumers}

From the consumer's utility maximization problem given by equations (1) and (2), the intertemporal optimality condition is derived:

$$
C_{t}^{-v}=\beta\left(1+i_{t}\right) \mathbb{E}_{t}\left(\frac{C_{t+1}^{-v} P_{t}}{P_{t+1}}\right),
$$

and

$$
\frac{1}{1+i_{t}}=\mathbb{E}_{t}\left(X_{t, t+1}\right)
$$

Also, the optimality condition for differentiated labor supply is given by

$$
C_{t}^{v}=\frac{w_{t}(h)}{P_{t}}=\frac{w_{t}}{P_{t}}
$$

Linear dis-utility in labor supply results in a homogenous wage rate.

Similarly for the foreign country, we have

$$
\begin{gathered}
\left(C_{t}^{*}\right)^{-v}=\beta\left(1+i_{t}^{*}\right) \mathbb{E}_{t}\left[\frac{\left(C_{t+1}^{*}\right)^{-v} P_{t}^{*}}{P_{t+1}^{*}}\right], \\
\frac{1}{1+i_{t}^{*}}=\mathbb{E}_{t}\left(X_{t, t+1}\right) \frac{S_{t+1}}{S_{t}}
\end{gathered}
$$

and

$$
\left(C_{t}^{*}\right)^{v}=\frac{w_{t}^{*}\left(h^{*}\right)}{P_{t}^{*}}=\frac{w_{t}^{*}}{P_{t}^{*}}
$$

where $S_{t}$ denotes the nominal exchange rate. By combining (57), (58), (60) and (61), under the assumption where both countries are equally wealthy initially, the following 
international risk sharing condition determines the real exchange rate $e_{t}$.

$$
C_{t}^{v}=e_{t}\left(C_{t}^{*}\right)^{v}
$$

where

$$
e_{t}=\frac{S_{t} P_{t}^{*}}{P_{t}}
$$

\section{Final Goods Producers}

The cost minimization problem by the final goods producer leads to

$$
P_{H, t}=\psi P_{t} \frac{Y_{H, t}^{\psi-1} Y_{F, t}^{1-\psi}}{\psi^{\psi}(1-\psi)^{1-\psi}}=\psi P_{t} \frac{Y_{t}}{Y_{H, t}}
$$

and

$$
P_{F, t}=(1-\psi) P_{t} \frac{Y_{t}}{Y_{F, t}} .
$$

By plugging them into production function (7),

$$
P_{t}=P_{H, t}^{\psi} P_{F, t}^{1-\psi}
$$

By solving similar cost minimization problem on equation (8), the standard definition of aggregate price index and relative demands are derived as

$$
P_{H, t}=\left[\int_{0}^{1} p_{t}(h)^{1-\sigma} \mathrm{d} h\right]^{\frac{1}{1-\sigma}},
$$

and

$$
y_{t}(h)=\left[\frac{p_{t}(h)}{P_{H, t}}\right]^{-\sigma} Y_{H, t} .
$$


Similarly, in the foreign country,

$$
\begin{gathered}
Y_{F, t}^{*}=(1-\psi)\left(\frac{P_{F, t}^{*}}{P_{t}^{*}}\right)^{-1} Y_{t}^{*}, \\
Y_{H, t}^{*}=\psi\left(\frac{P_{H, t}^{*}}{P_{t}^{*}}\right)^{-1} Y_{t}^{*}, \\
P_{t}^{*}=\left(P_{H, t}^{*}\right)^{\psi}\left(P_{F, t}^{*}\right)^{1-\psi}, \\
P_{H, t}^{*}=\left[\int_{0}^{1} p_{t}^{*}(h)^{1-\sigma} \mathrm{d} h\right]^{\frac{1}{1-\sigma}},
\end{gathered}
$$

and

$$
y_{t}^{*}(h)=\left[\frac{p_{t}^{*}(h)}{P_{H, t}^{*}}\right]^{-\sigma} Y_{H, t}^{*} .
$$

\section{Intermediated Goods Producers}

From the profit maximization problem in equation (6) by intermediate-goods producer

$h$, together with equations (3) and (68), the optimal price setting conditions are derived as

$$
p_{t}(h)=\frac{\sigma R_{t}(h) w_{t}}{\left(1+\tau_{t}\right)(\sigma-1) \exp \left(z_{t}\right)}=\frac{\exp \left(\mu_{t}\right) R_{t}(h) w_{t}}{\exp \left(z_{t}\right)}
$$

where we also assume

$$
\frac{\sigma}{(1+\tau)(\sigma-1)}=1
$$

Similarly, for the foreign firms,

$$
p_{t}^{*}\left(h^{*}\right)=R_{t}^{*}\left(h^{*}\right) w_{t}^{*},
$$

and the law of one price implies

$$
p_{t}\left(h^{*}\right)=S_{t} p_{t}^{*}\left(h^{*}\right) .
$$




\section{Banks}

The loan demand is expressed by combining equations (3), (4), (5), (59), (67), (68), (72), (73) and (74) as

$$
q_{t}(h)=\frac{w_{t}}{\exp \left(z_{t}\right)}\left[\frac{R_{t}(h)}{R_{t}}\right]^{-\sigma}\left(Y_{H, t}+Y_{H, t}^{*}\right)
$$

To maximize the profit maximization in equation (10) together with equation (76),

the private bank optimally sets its loan rate $\tilde{R}_{t}$ to satisfy

$\mathbb{E}_{t} \sum_{T=t}^{\infty}(\beta \phi)^{T-t} \frac{P_{t} C_{T}^{-v} w_{T} \exp \left(z_{t}\right)\left(Y_{H, T}+Y_{H, T}^{*}\right)}{P_{T} C_{t}^{-v} w_{t} \exp \left(z_{T}\right)\left(Y_{H, t}+Y_{H, t}^{*}\right)}\left(\frac{R_{t}}{R_{T}}\right)^{-\sigma-1}\left[\frac{\tilde{R}_{t}}{R_{t}} \frac{R_{t}}{R_{T}}-\frac{\sigma\left(1+i_{T}\right) u_{T}}{(1+\tau)(\sigma-1) R_{T}}\right]=0$.

From equation (15),

$$
\frac{\tilde{R}_{t}}{R_{t}}=\left[\frac{1-\phi\left(\frac{R_{t-1}}{R_{t}}\right)^{1-\sigma}}{1-\phi}\right]^{\frac{1}{1-\sigma}} .
$$

By combining equations (77) and (78),

$$
\left[\frac{1-\phi\left(\frac{R_{t-1}}{R_{t}}\right)^{1-\sigma}}{1-\phi}\right]^{\frac{1}{1-\sigma}} F_{t}=K_{t}
$$

where

$$
\begin{aligned}
F_{t} & \equiv \mathbb{E}_{t} \sum_{T=t}^{\infty}(\beta \phi)^{T-t} \frac{P_{t} C_{T}^{-v} w_{T} \exp \left(z_{t}\right)\left(Y_{H, T}+Y_{H, T}^{*}\right)}{P_{T} C_{t}^{-v} w_{t} \exp \left(z_{T}\right)\left(Y_{H, t}+Y_{H, t}^{*}\right)}\left(\frac{R_{t}}{R_{T}}\right)^{-\sigma} \\
& =1+\beta \phi \mathbb{E}_{t} \frac{P_{t} C_{t+1}^{-v} w_{t+1} \exp \left(z_{t}\right)\left(Y_{H, t+1}+Y_{H, t+1}^{*}\right)}{P_{t+1} C_{t}^{-v} w_{t} \exp \left(z_{t+1}\right)\left(Y_{H, t}+Y_{H, t}^{*}\right)}\left(\frac{R_{t}}{R_{t+1}}\right)^{-\sigma} F_{t+1},
\end{aligned}
$$


and

$$
\begin{aligned}
K_{t} & \equiv \mathbb{E}_{t} \sum_{T=t}^{\infty}(\beta \phi)^{T-t} \frac{P_{t} C_{T}^{-v} w_{T} \exp \left(z_{t}\right)\left(Y_{H, T}+Y_{H, T}^{*}\right)}{P_{T} C_{t}^{-v} w_{t} \exp \left(z_{T}\right)\left(Y_{H, t}+Y_{H, t}^{*}\right)}\left(\frac{R_{t}}{R_{T}}\right)^{-\sigma-1} \frac{\sigma\left(1+i_{T}\right) u_{T}}{(1+\tau)(\sigma-1) R_{T}} \\
& \left.=\frac{\left(1+i_{t}\right) \exp \left(\mu_{t}\right) \exp \left(u_{t}\right)}{R_{t}}+\beta \phi \mathbb{E}_{t} \frac{P_{t} C_{t+1}^{-v} w_{t+1} \exp \left(z_{t}\right)\left(Y_{H, t+1}+Y_{H, t+1}^{*}\right)}{P_{t+1} C_{t}^{-v} w_{t} \exp \left(z_{t+1}\right)\left(Y_{H, t}+Y_{H, t}^{*}\right)}\right)^{-\sigma-1} K_{t+1} K_{t+1} .
\end{aligned}
$$

Similarly, for loan rate settings in the foreign country,

$$
\left[\frac{1-\phi\left(\frac{R_{t-1}^{*}}{R_{t}^{*}}\right)^{1-\sigma}}{1-\phi}\right]^{\frac{1}{1-\sigma}} F_{t}^{*}=K_{t}^{*}
$$

where

$$
F_{t}^{*}=1+\beta \phi \mathbb{E}_{t} \frac{P_{t}^{*}\left(C_{t+1}^{*}\right)^{v} w_{t+1}^{*}\left(Y_{F, t+1}+Y_{F, t+1}^{*}\right)}{P_{t+1}^{*}\left(C_{t}^{*}\right)^{v} w_{t}^{*}\left(Y_{F, t}+Y_{F, t}^{*}\right)}\left(\frac{R_{t}^{*}}{R_{t+1}^{*}}\right)^{-\sigma} F_{t+1}^{*},
$$

and

$$
K_{t}^{*}=\frac{\left(1+i_{t}^{*}\right)}{R_{t}^{*}}+\beta \phi \mathbb{E}_{t} \frac{P_{t}^{*}\left(C_{t+1}^{*}\right)^{-v} w_{t+1}^{*}\left(Y_{F, t+1}+Y_{F, t+1}^{*}\right)}{P_{t+1}^{*}\left(C_{t}^{*}\right)^{-v} w_{t}^{*}\left(Y_{F, t}+Y_{F, t}^{*}\right)}\left(\frac{R_{t}^{*}}{R_{t+1}^{*}}\right)^{-\sigma-1} K_{t+1}^{*} .
$$

\section{Aggregation}

With equations (3), (5), (15), (64), (67), (70), (68), (73) and (74),

$$
\psi \Delta_{t}\left(\frac{P_{t} Y_{t}}{P_{H, t}}+\frac{P_{t}^{*} Y_{t}^{*}}{P_{H, t}^{*}}\right)=\exp \left(z_{t}\right) l_{t}
$$

where

$$
l_{t} \equiv \int_{0}^{1} l_{t}(h) \mathrm{d} h
$$


By using equations (15) and (78), this can be expressed as a dynamic equation.

$$
\begin{aligned}
\Delta_{t} & \equiv \int_{0}^{1}\left[\frac{R_{t}(h)}{R_{t}}\right]^{-\sigma} \mathrm{d} h \\
& =(1-\phi)\left[\frac{1-\phi\left(\frac{R_{t-1}}{R_{t}}\right)^{1-\sigma}}{1-\phi}\right]^{\frac{\sigma}{\sigma-1}}+\phi\left(\frac{R_{t-1}}{R_{t}}\right)^{-\sigma} \Delta_{t-1}
\end{aligned}
$$

Similarly for the foreign country,

$$
\left(\frac{P_{t} Y_{t}}{P_{F, t}}+\frac{P_{t}^{*} Y_{t}^{*}}{P_{F, t}^{*}}\right)(1-\psi) \Delta_{t}^{*}=l_{t}^{*},
$$

and

$$
\Delta_{t}^{*}=(1-\phi)\left[\frac{1-\phi\left(\frac{R_{t-1}^{*}}{R_{t}^{*}}\right)^{1-\sigma}}{1-\phi}\right]^{\frac{\sigma}{\sigma-1}}+\phi\left(\frac{R_{t-1}^{*}}{R_{t}^{*}}\right)^{-\sigma} \Delta_{t-1}^{*} .
$$

By combining (67), (74) and (15), the price index is related to marginal costs:

$$
P_{H, t}=\frac{\exp \left(\mu_{t}\right) w_{t} R_{t}}{\exp \left(z_{t}\right)}
$$

With equation (5),

$$
P_{H, t}^{*}=\frac{\exp \left(\mu_{t}\right) w_{t} R_{t}}{S_{t} \exp \left(z_{t}\right)}
$$

Similarly, for price settings by the foreign firms,

$$
P_{F, t}^{*}=w_{t}^{*} R_{t}^{*}
$$

and

$$
P_{F, t}=S_{t} w_{t}^{*} R_{t}^{*} .
$$




\section{System of Equations}

27 Equations (12), (13), (57), (59), (60), (62), (63), (64), (65), (66), (67), (70) (71), (79), (81), (80), (82) (84), (83), (85), (86), (87) (88), (89), (72), (91) and (92) determines dynamic paths of $\pi_{t}, \pi_{t}^{*}, \tilde{w}_{t}, \tilde{w}_{t}^{*}, e_{t}, Y_{H, t}, Y_{F, t}, Y_{t}, Y_{H, t}^{*}, Y_{F, t}^{*}, Y_{t}^{*}, R_{t}, F_{t}, K_{t}, R_{t}^{*}, F_{t}^{*}, K_{t}^{*}$, $l_{t}, \Delta_{t}, l_{t}^{*}, \Delta_{t}^{*}, p_{H, t}, p_{H, t}^{*}, p_{F, t}^{*}, p_{F, t}, C_{t}$ and $C_{t}^{*}$ under the optimal monetary policy for $i_{t}$ and $i_{t}^{*}$.

Nominal variables are de-trended as

$$
\begin{aligned}
& \pi_{t} \equiv \frac{P_{t}}{P_{t-1}}, \tilde{w}_{t} \equiv \frac{w_{t}}{P_{t}}, \tilde{w}_{t}^{*} \equiv \frac{w_{t}^{*}}{P_{t}^{*}}, p_{H, t} \equiv \frac{P_{H, t}}{P_{t}}, p_{H, t}^{*} \equiv \frac{P_{H, t}^{*}}{P_{t}^{*}}, p_{F, t} \equiv \frac{P_{F, t}}{P_{t}}, p_{F, t}^{*} \equiv \frac{P_{F, t}^{*}}{P_{t}^{*}} \\
& C_{t}^{-v}=\beta\left(1+i_{t}\right) \mathbb{E}_{t}\left(\frac{C_{t+1}^{-v}}{\pi_{t+1}}\right) \\
& C_{t}^{v}=\tilde{w}_{t} \\
& \left(C_{t}^{*}\right)^{-v}=\beta\left(1+i_{t}^{*}\right) \mathbb{E}_{t}\left[\frac{\left(C_{t+1}^{*}\right)^{-v}}{\pi_{t+1}^{*}}\right], \\
& \left(C_{t}^{*}\right)^{v}=\tilde{w}_{t}^{*} \\
& C_{t}^{v}=e_{t}\left(C_{t}^{*}\right)^{v} \\
& Y_{H, t}=\psi\left(p_{H, t}\right)^{-1} Y_{t} \\
& Y_{F, t}=(1-\psi)\left(p_{F, t}\right)^{-1} Y_{t} \\
& Y_{F, t}^{*}=(1-\psi)\left(p_{F, t}^{*}\right)^{-1} Y_{t}^{*}, \\
& Y_{H, t}^{*}=\psi\left(p_{H, t}^{*}\right)^{-1} Y_{t}^{*}, \\
& {\left[\frac{1-\phi\left(\frac{R_{t-1}}{R_{t}}\right)^{1-\sigma}}{1-\phi}\right]^{\frac{1}{1-\sigma}} F_{t}=K_{t},}
\end{aligned}
$$




$$
\begin{aligned}
& F_{t}=1+\beta \phi \mathbb{E}_{t} \frac{C_{t+1}^{-v} \tilde{w}_{t+1} \exp \left(z_{t}\right)\left(Y_{H, t+1}+Y_{H, t+1}^{*}\right)}{C_{t}^{-v} \tilde{w}_{t} \exp \left(z_{t+1}\right)\left(Y_{H, t}+Y_{H, t}^{*}\right)}\left(\frac{R_{t}}{R_{t+1}}\right)^{-\sigma} F_{t+1}, \\
& K_{t}=\frac{\left(1+i_{t}\right) \exp \left(\mu_{t}\right) \exp \left(u_{t}\right)}{R_{t}}+\beta \phi \mathbb{E}_{t} \frac{C_{t+1}^{-v} \tilde{w}_{t+1} \exp \left(z_{t}\right)\left(Y_{H, t+1}+Y_{H, t+1}^{*}\right)}{C_{t}^{-v} \tilde{w}_{t} \exp \left(z_{t+1}\right)\left(Y_{H, t}+Y_{H, t}^{*}\right)}\left(\frac{R_{t}}{R_{t+1}}\right)^{-\sigma-1} K_{t+1} \text {, } \\
& {\left[\frac{1-\phi\left(\frac{R_{t-1}^{*}}{R_{t}^{*}}\right)^{1-\sigma}}{1-\phi}\right]^{\frac{1}{1-\sigma}} F_{t}^{*}=K_{t}^{*}} \\
& F_{t}^{*}=1+\beta \phi \mathbb{E}_{t} \frac{\left(C_{t+1}^{*}\right)^{-v} \tilde{w}_{t+1}^{*}\left(Y_{F, t+1}+Y_{F, t+1}^{*}\right)}{\left(C_{t}^{*}\right)^{-v} \tilde{w}_{t}^{*}\left(Y_{F, t}+Y_{F, t}^{*}\right)}\left(\frac{R_{t}^{*}}{R_{t+1}^{*}}\right)^{-\sigma} F_{t+1}^{*}, \\
& K_{t}^{*}=\frac{1+i_{t}^{*}}{R_{t}^{*}}+\beta \phi \mathbb{E}_{t} \frac{\left(C_{t+1}^{*}\right)^{-v} \tilde{w}_{t+1}^{*}\left(Y_{F, t+1}+Y_{F, t+1}^{*}\right)}{\left(C_{t}^{*}\right)^{-v} \tilde{w}_{t}^{*}\left(Y_{F, t}+Y_{F, t}^{*}\right)}\left(\frac{R_{t}^{*}}{R_{t+1}^{*}}\right)^{-\sigma-1} K_{t+1}^{*}, \\
& \left(\frac{Y_{t}}{p_{H, t}}+\frac{Y_{t}^{*}}{p_{H, t}^{*}}\right) \psi \Delta_{t}=\exp \left(z_{t}\right) l_{t} \\
& \Delta_{t}=(1-\phi)\left[\frac{1-\phi\left(\frac{R_{t-1}}{R_{t}}\right)^{1-\sigma}}{1-\phi}\right]^{\frac{\sigma}{\sigma-1}}+\phi\left(\frac{R_{t-1}}{R_{t}}\right)^{-\sigma} \Delta_{t-1} \\
& \left(\frac{Y_{t}}{p_{F, t}}+\frac{Y_{t}^{*}}{p_{F, t}^{*}}\right)(1-\psi) \Delta_{t}^{*}=\exp \left(z_{t}^{*}\right) l_{t}^{*}, \\
& \Delta_{t}^{*}=(1-\phi)\left[\frac{1-\phi\left(\frac{R_{t-1}^{*}}{R_{t}^{*}}\right)^{1-\sigma}}{1-\phi}\right]^{\frac{\sigma}{\sigma-1}}+\phi\left(\frac{R_{t-1}^{*}}{R_{t}^{*}}\right)^{-\sigma} \Delta_{t-1}^{*}, \\
& p_{H, t}=\frac{\tilde{w}_{t} R_{t} \exp \left(\mu_{t}\right)}{\exp \left(z_{t}\right)}, \\
& p_{H, t}^{*}=\frac{\tilde{w}_{t} R_{t} \exp \left(\mu_{t}\right)}{e_{t} \exp \left(z_{t}\right)} \text {, } \\
& p_{F, t}^{*}=\tilde{w}_{t}^{*} R_{t}^{*}, \\
& p_{F, t}=e_{t} \tilde{w}_{t}^{*} R_{t}^{*}, \\
& C_{t}=Y_{t},
\end{aligned}
$$




$$
\begin{gathered}
C_{t}^{*}=Y_{t}^{*}, \\
1=p_{H, t}^{\psi} p_{F, t}^{1-\psi},
\end{gathered}
$$

and

$$
1=\left(p_{H, t}^{*}\right)^{\psi}\left(p_{F, t}^{*}\right)^{1-\psi} .
$$

Under the assumption $\psi=0.5$, these collapse to equations (16) to (26). 


\section{Appendix B: Ramsey Policy}

\section{Cooperation}

The optimal monetary policy under cooperation is determined by equations below:

$$
\begin{aligned}
& 2 Y_{t}^{-v}+\frac{\lambda_{t}^{3}}{Y_{t-1}}-\mathbb{E}_{t} \frac{\beta \lambda_{t+1}^{3} Y_{t+1}}{Y_{t}^{2}}+\frac{2 v \lambda_{t}^{12} Y_{t}^{2 v-1} \exp \left(\mu_{t}\right) R_{t} R_{t}^{*}}{\exp \left(z_{t}\right)} \\
& -\frac{(1-v) Y_{t}^{-v} \Delta_{t}}{\exp \left(\mu_{t}\right) R_{t}}-\frac{Y_{t}^{-v} \Delta_{t}^{*}}{R_{t}^{*}}=0 \\
& -\lambda_{t}^{10}+\mathbb{E}_{t} \beta \lambda_{t+1}^{10} \phi \pi_{t+1}^{\sigma}-\frac{Y_{t}^{1-v}}{\exp \left(\mu_{t}\right) R_{t}}=0 \\
& \frac{\lambda_{t}^{1}}{R_{t-1}}-\mathbb{E}_{t} \frac{\beta \lambda_{t+1}^{1} R_{t+1}}{R_{t}^{2}}+\frac{\lambda_{t}^{12} \exp \left(\mu_{t}\right) R_{t}^{*}}{\exp \left(z_{t}\right)} Y_{t}^{2 v}+\frac{Y_{t}^{1-v} \Delta_{t}}{R_{t}^{2}}=0, \\
& -\lambda_{t}^{11}+\mathbb{E}_{t} \beta \lambda_{t+1}^{11} \phi\left(\pi_{t+1}^{*}\right)^{\sigma}-\frac{Y_{t}^{1-v}}{R_{t}^{*}}=0 \\
& \frac{\lambda_{t}^{2}}{R_{t-1}^{*}}-\frac{\beta \lambda_{t+1}^{2} R_{t+1}^{*}}{\left(R_{t}^{*}\right)^{2}}+\frac{\lambda_{t}^{12} \exp \left(\mu_{t}\right) R_{t}}{\exp \left(z_{t}\right)} Y_{t}^{2 v}+\frac{Y_{t}^{1-v} \Delta_{t}^{*}}{\left(R_{t}^{*}\right)^{2}}=0, \\
& -\lambda_{t}^{1}+\lambda_{t-1}^{5}(\sigma-1) \phi g_{t}^{1-v} \pi_{t}^{\sigma-2} F_{t} \\
& +\lambda_{t}^{10} \phi \sigma\left[\pi_{t}^{\sigma-1} \Delta_{t-1}-\left(\frac{1-\phi \pi_{t}^{\sigma-1}}{1-\phi}\right)^{\frac{1}{\sigma-1}} \pi_{t}^{\sigma-2}\right]=0 \text {, } \\
& -\lambda_{t}^{2}+\lambda_{t-1}^{8}(\sigma-1) \phi g_{t}^{1-v}\left(\pi_{t}^{*}\right)^{\sigma-2} F_{t}^{*} \\
& +\lambda_{t}^{11} \sigma \phi\left\{\left(\pi_{t}^{*}\right)^{\sigma-1} \Delta_{t-1}^{*}-\left[\frac{1-\phi\left(\pi_{t}^{*}\right)^{\sigma-1}}{1-\phi}\right]^{\frac{1}{\sigma-1}}\left(\pi_{t}^{*}\right)^{\sigma-2}\right\}=0 \text {, } \\
& -\lambda_{t}^{3}+\frac{\lambda_{t-1}^{5}(1-v) \phi \exp \left(z_{t}\right) g_{t}^{-v} \pi_{t}^{\sigma-1} F_{t}}{\exp \left(z_{t-1}\right)}+\lambda_{t-1}^{8}(1-v) \phi g_{t}^{-v}\left(\pi_{t}^{*}\right)^{\sigma-1} F_{t}^{*}=0 \\
& -\lambda_{t}^{5}+\lambda_{t-1}^{5} \phi g_{t}^{1-v} \pi_{t}^{\sigma-1}=0
\end{aligned}
$$




$$
\begin{gathered}
-\lambda_{t}^{8}+\lambda_{t-1}^{8} \phi g_{t}^{1-v}\left(\pi_{t}^{*}\right)^{\sigma-1}=0, \\
\lambda_{t}^{4}=0, \\
\lambda^{6}=0, \\
\lambda_{t}^{7}=0, \\
\lambda^{9}=0, \\
\lambda_{t}^{13}=1,
\end{gathered}
$$

and

$$
\lambda_{t}^{14}=1 .
$$

$\lambda^{i}$ denotes the Lagrange multiplier for the constraints (16) to (26), respectively.

\section{Noncooperation}

The optimal monetary policy under noncooperation is determined by equations below:

\section{Domestic}

$$
\begin{gathered}
Y_{t}^{-v}+\frac{\tilde{\lambda}_{t}^{3}}{Y_{t-1}}-\mathbb{E}_{t} \frac{\beta \tilde{\lambda}_{t+1}^{3} Y_{t+1}}{Y_{t}^{2}}+\frac{2 v \tilde{\lambda}_{t}^{12} Y_{t}^{2 v-1} \exp \left(\mu_{t}\right) R_{t} R_{t}^{*}}{\exp \left(z_{t}\right)} \\
-\frac{(1-v) Y_{t}^{-v} \Delta_{t}}{\exp \left(\mu_{t}\right) R_{t}}=0, \\
-\tilde{\lambda}_{t}^{10}+\mathbb{E}_{t} \beta \tilde{\lambda}_{t+1}^{10} \phi \pi_{t+1}^{\sigma}-\frac{Y_{t}^{1-v}}{\exp \left(\mu_{t}\right) R_{t}}=0, \\
\frac{\tilde{\lambda}_{t}^{1}}{R_{t-1}}-\mathbb{E}_{t} \frac{\beta \tilde{\lambda}_{t+1}^{1} R_{t+1}}{R_{t}^{2}}+\frac{\tilde{\lambda}_{t}^{12} \exp \left(\mu_{t}\right) R_{t}^{*}}{\exp \left(z_{t}\right)} Y_{t}^{2 v}+\frac{Y_{t}^{1-v} \Delta_{t}}{\exp \left(\mu_{t}\right) R_{t}^{2}}=0, \\
-\tilde{\lambda}_{t}^{11}+\mathbb{E}_{t} \beta \tilde{\lambda}_{t+1}^{11} \phi\left(\pi_{t+1}^{*}\right)^{\sigma}=0,
\end{gathered}
$$




$$
\begin{aligned}
& \frac{\tilde{\lambda}_{t}^{2}}{R_{t-1}^{*}}-\mathbb{E}_{t} \frac{\beta \tilde{\lambda}_{t+1}^{2} R_{t+1}^{*}}{\left(R_{t}^{*}\right)^{2}}-\frac{\tilde{\lambda}_{t}^{9}\left(1+i_{t}^{*}\right) \exp \left(u_{t}^{*}\right)}{\left(R_{t}^{*}\right)^{2}}+\frac{\tilde{\lambda}_{t}^{12} R_{t}}{\exp \left(z_{t}\right)} Y_{t}^{2 v}=0, \\
& -\tilde{\lambda}_{t}^{1}+\tilde{\lambda}_{t-1}^{5}(\sigma-1) \phi g_{t}^{1-v} \pi_{t}^{\sigma-2} F_{t} \\
& +\tilde{\lambda}_{t}^{10} \phi \sigma\left[\pi_{t}^{\sigma-1} \Delta_{t-1}-\left(\frac{1-\phi \pi_{t}^{\sigma-1}}{1-\phi}\right)^{\frac{1}{\sigma-1}} \pi_{t}^{\sigma-2}\right]=0, \\
& -\tilde{\lambda}_{t}^{2}-\tilde{\lambda}_{t}^{7}\left[\frac{1-\phi\left(\pi_{t}^{*}\right)^{\sigma-1}}{1-\phi}\right]^{\frac{\sigma}{1-\sigma}} \frac{\phi\left(\pi_{t}^{*}\right)^{\sigma-2}}{1-\phi} F_{t}^{*}+\tilde{\lambda}_{t-1}^{8}(\sigma-1) \phi g_{t}^{1-v}\left(\pi_{t}^{*}\right)^{\sigma-2} F_{t}^{*} \\
& +\tilde{\lambda}_{t-1}^{9} \sigma \phi g_{t}^{1-v}\left(\pi_{t}^{*}\right)^{\sigma-1} K_{t}^{*} \\
& +\tilde{\lambda}_{t}^{11} \sigma \phi\left\{\left(\pi_{t}^{*}\right)^{\sigma-1} \Delta_{t-1}^{*}-\left[\frac{1-\phi\left(\pi_{t}^{*}\right)^{\sigma-1}}{1-\phi}\right]^{\frac{1}{\sigma-1}}\left(\pi_{t}^{*}\right)^{\sigma-2}\right\}=0, \\
& -\tilde{\lambda}_{t}^{3}+\tilde{\lambda}_{t-1}^{5}(1-v) \phi g_{t}^{-v} \pi_{t}^{\sigma-1} F_{t}+\tilde{\lambda}_{t-1}^{8}(1-v) \phi g_{t}^{-v}\left(\pi_{t}^{*}\right)^{\sigma-1} F_{t}^{*}+\tilde{\lambda}_{t-1}^{9}(1-v) \phi g_{t}^{-v}\left(\pi_{t}^{*}\right)^{\sigma} K_{t}^{*}=0, \\
& -\tilde{\lambda}_{t}^{5}+\tilde{\lambda}_{t-1}^{5} \phi g_{t}^{1-v} \pi_{t}^{\sigma-1}=0, \\
& -\tilde{\lambda}_{t}^{7}\left[\frac{1-\phi\left(\pi_{t}^{*}\right)^{\sigma-1}}{1-\phi}\right]^{\frac{1}{1-\sigma}}-\tilde{\lambda}_{t}^{8}+\tilde{\lambda}_{t-1}^{8} \phi g_{t}^{1-v}\left(\pi_{t}^{*}\right)^{\sigma-1}=0, \\
& \tilde{\lambda}_{t}^{7}-\tilde{\lambda}_{t}^{9}+\tilde{\lambda}_{t-1}^{9} \phi g_{t}^{1-v}\left(\pi_{t}^{*}\right)^{\sigma}=0 \\
& \tilde{\lambda}_{t}^{4}=0, \\
& \tilde{\lambda}_{t}^{6}=0, \\
& \tilde{\lambda}_{t}^{13}=1,
\end{aligned}
$$

and

$$
\tilde{\lambda}_{t}^{14}=0 .
$$


$\tilde{\lambda}^{i}$ denotes the Lagrange multiplier for the constraints (16) to (26) for the domestic central bank's maximization problem.

\section{Foreign}

$$
\begin{aligned}
& Y_{t}^{-v}+\frac{\bar{\lambda}_{t}^{3}}{Y_{t-1}}-\mathbb{E}_{t} \frac{\beta \bar{\lambda}_{t+1}^{3} Y_{t+1}}{Y_{t}^{2}}+\frac{2 v \bar{\lambda}_{t}^{12} Y_{t}^{2 v-1} \exp \left(\mu_{t}\right) R_{t} R_{t}^{*}}{\exp \left(z_{t}\right) \exp \left(z_{t}^{*}\right)} \\
& -\frac{2(1-\psi)(1-v) Y_{t}^{-v} \Delta_{t}^{*}}{\gamma R_{t}^{*}}=0, \\
& -\bar{\lambda}_{t}^{10}+\mathbb{E}_{t} \beta \bar{\lambda}_{t+1}^{10} \phi \pi_{t+1}^{\sigma}=0, \\
& \frac{\bar{\lambda}_{t}^{1}}{R_{t-1}}-\mathbb{E}_{t} \frac{\beta \bar{\lambda}_{t+1}^{1} R_{t+1}}{R_{t}^{2}}-\frac{\bar{\lambda}_{t}^{6}\left(1+i_{t}\right) \exp \left(\mu_{t}\right) \exp \left(u_{t}\right)}{R_{t}^{2}}+\frac{\bar{\lambda}_{t}^{12} \exp \left(\mu_{t}\right) R_{t}^{*}}{\exp \left(z_{t}\right)} Y_{t}^{2 v}=0, \\
& -\bar{\lambda}_{t}^{11}+\mathbb{E}_{t} \beta \bar{\lambda}_{t+1}^{11} \phi\left(\pi_{t+1}^{*}\right)^{\sigma}-\frac{Y_{t}^{1-v}}{R_{t}^{*}}=0, \\
& +\bar{\lambda}_{t}^{2} \frac{1}{R_{t-1}^{*}}-\beta \bar{\lambda}_{t+1}^{2} \frac{R_{t+1}^{*}}{\left(R_{t}^{*}\right)^{2}}+\bar{\lambda}_{t}^{12} Y_{t}^{2 v} \frac{R_{t}}{\exp \left(z_{t}\right)}+\frac{Y_{t}^{1-v} \Delta_{t}^{*}}{\left(R_{t}^{*}\right)^{2}}=0, \\
& -\bar{\lambda}_{t}^{2}+\bar{\lambda}_{t-1}^{8}(\sigma-1) \phi g_{t}^{1-v}\left(\pi_{t}^{*}\right)^{\sigma-2} F_{t}^{*} \\
& +\bar{\lambda}_{t}^{11} \sigma \phi\left\{\left(\pi_{t}^{*}\right)^{\sigma-1} \Delta_{t-1}^{*}-\left[\frac{1-\phi\left(\pi_{t}^{*}\right)^{\sigma-1}}{1-\phi}\right]^{\frac{1}{\sigma-1}}\left(\pi_{t}^{*}\right)^{\sigma-2}\right\}=0 \text {, } \\
& -\bar{\lambda}_{t}^{3}+\bar{\lambda}_{t-1}^{5}(1-v) \phi g_{t}^{-v} \pi_{t}^{\sigma-1} F_{t} \\
& +\bar{\lambda}_{t-1}^{6}(1-v) \phi g_{t}^{-v} \pi_{t}^{\sigma} K_{t}+\bar{\lambda}_{t-1}^{8}(1-v) \phi g_{t}^{-v}\left(\pi_{t}^{*}\right)^{\sigma-1} F_{t}^{*}=0, \\
& -\bar{\lambda}_{t}^{4}\left(\frac{1-\phi \pi_{t}^{\sigma-1}}{1-\phi}\right)^{\frac{1}{1-\sigma}}-\bar{\lambda}_{t}^{5}+\bar{\lambda}_{t-1}^{5} \phi g_{t}^{1-v} \pi_{t}^{\sigma-1}=0, \\
& \bar{\lambda}_{t}^{4}-\bar{\lambda}_{t}^{6}+\bar{\lambda}_{t-1}^{6} \phi g_{t}^{1-v} \pi_{t}^{\sigma}, \\
& -\bar{\lambda}_{t}^{8}+\bar{\lambda}_{t-1}^{8} \phi g_{t}^{1-v}\left(\pi_{t}^{*}\right)^{\sigma-1}=0,
\end{aligned}
$$




$$
\begin{aligned}
& \bar{\lambda}_{t}^{7}=0, \\
& \bar{\lambda}_{t}^{9}=0, \\
& \bar{\lambda}_{t}^{13}=0,
\end{aligned}
$$

and

$$
\bar{\lambda}_{t}^{14}=1
$$

$\bar{\lambda}^{i}$ denotes the Lagrange multiplier for the constraints (16) to (26) for the foreign central bank's maximization problem.

\section{Ramsey Optimal Steady State}

\section{Cooperation}

The Ramsey optimal steady states under cooperation is as follows:

$$
\begin{gathered}
F=K=F^{*}=K^{*}=\frac{1}{1-\beta \phi}, \\
\Delta=\Delta^{*}=1, \\
1+i=1+i^{*}=1, \\
Y=l=l^{*}=1, \\
R=R^{*}=1, \\
\lambda^{1}=\lambda^{2}=\lambda^{3}=\lambda^{4}=\lambda^{5}=\lambda^{6}=\lambda^{7}=\lambda^{8}=\lambda^{9}=0, \\
\lambda^{10}=\lambda^{11}=\frac{1}{\beta \phi-1}, \\
\lambda^{12}=-1
\end{gathered}
$$


and

$$
\lambda^{13}=\lambda^{14}=1 .
$$

\section{Noncooperation}

On the other hand, the Ramsey optimal steady states under noncooperative framework are as follows:

$$
\begin{aligned}
& F=K=F^{*}=K^{*}=\frac{1}{1-\beta \phi}, \\
& \Delta=\Delta^{*}=1 \\
& 1+i=1+i^{*}=(1+v), \\
& Y=l=l^{*}=\left(\frac{1}{1+v}\right)^{\frac{1}{v}} \\
& R=R^{*}=1+v, \\
& \tilde{\lambda}^{1}=\tilde{\lambda}^{2}=\tilde{\lambda}^{3}=\tilde{\lambda}^{4}=\tilde{\lambda}^{5}=\tilde{\lambda}^{6}=0, \\
& \tilde{\lambda}^{7}=(\phi-1)\left(\frac{1}{1+v}\right)^{\frac{1}{v}} \\
& \tilde{\lambda}^{8}=\left(\frac{1}{1+v}\right)^{\frac{1}{v}} \\
& \tilde{\lambda}^{9}=\tilde{\lambda}^{12}=-\left(\frac{1}{1+v}\right)^{\frac{1}{v}} \\
& \tilde{\lambda}^{10}=\frac{1}{\beta \phi-1}\left(\frac{1}{1+v}\right)^{\frac{1}{v}}, \\
& \tilde{\lambda}^{11}=0, \\
& \tilde{\lambda}^{13}=1 \\
& \tilde{\lambda}^{14}=0 \\
& \bar{\lambda}^{1}=\bar{\lambda}^{2}=\bar{\lambda}^{3}=\bar{\lambda}^{7}=\bar{\lambda}^{8}=\bar{\lambda}^{9}=\bar{\lambda}^{10}=0,
\end{aligned}
$$




$$
\begin{gathered}
\bar{\lambda}^{4}=(\phi-1)\left(\frac{1}{1+v}\right)^{\frac{1}{v}}, \\
\bar{\lambda}^{5}=\left(\frac{1}{1+v}\right)^{\frac{1}{v}}, \\
\bar{\lambda}^{6}=\bar{\lambda}^{12}=-\left(\frac{1}{1+v}\right)^{\frac{1}{v}} \\
\bar{\lambda}^{11}=\frac{1}{(\beta \phi-1)}\left(\frac{1}{1+v}\right)^{\frac{1}{v}} \\
\bar{\lambda}^{13}=0
\end{gathered}
$$

and

$$
\bar{\lambda}^{14}=1 .
$$




\section{Appendix C: Steady State Welfare Comparison}

When $v \neq 1$, welfare under cooperation is given by

$$
W_{C}=W_{C}^{*}=\frac{1}{1-\beta} \frac{v}{1-v}
$$

while that under noncooperation is

$$
W_{N}=W_{N}^{*}=\frac{1}{1-\beta}\left(\frac{1}{1+v}\right)^{\frac{1}{v}} \frac{2 v}{1-v}
$$

Thus, the steady state welfare difference is

$$
\begin{aligned}
W_{C}-W_{N} & =\frac{1}{1-\beta} \frac{v}{1-v}-\frac{1}{1-\beta}\left(\frac{1}{1+v}\right)^{\frac{1}{v}} \frac{2 v}{1-v} \\
& =\frac{1}{1-\beta} \frac{v}{1-v}\left[1-2\left(\frac{1}{1+v}\right)^{\frac{1}{v}}\right] .
\end{aligned}
$$

Equation (36) depicts that $\left(\frac{1}{1+v}\right)^{\frac{1}{v}}$ is always increasing in $v$ and it takes $\frac{1}{2}$ when $v=1$. Thus,

$$
W_{C}-W_{N}>0
$$

when

$$
0<v<1
$$

and

$$
v>1
$$

When $v=1$, welfare under cooperation is

$$
W_{C}=W_{C}^{*}=-\frac{1}{1-\beta},
$$


while that under noncooperation is

$$
\begin{aligned}
W_{N} & =W_{N}^{*}=\frac{1}{1-\beta}\left[\log \left(\frac{1}{2}\right)-\frac{1}{2}\right] \\
& =-\frac{1}{1-\beta}\left[\log (2)+\frac{1}{2}\right]<W_{C} .
\end{aligned}
$$




\section{Appendix D: Second Order Approximation of Loan Phillips Curve}

Here, the second order approximation of the loan Phillips curve in the domestic country will be described. First, we denote

$$
r_{t}^{*}=\frac{\tilde{R}_{t}}{R_{t}} .
$$

Then, equation (79) can be written as

$$
r_{t}^{*} F_{t}=K_{t}
$$

or

$$
\hat{r}_{t}^{*}+\hat{F}_{t}=\hat{K}_{t}
$$

where $F_{t}$ and $K_{t}$ are slightly differently defined from equations (17) and (18):

$$
\begin{gathered}
F_{t} \equiv \mathbb{E}_{t} \sum_{T=t}^{\infty}(\beta \phi)^{T-t} f_{t, T}, \\
K_{t} \equiv \mathbb{E}_{t} \sum_{T=t}^{\infty}(\beta \phi)^{T-t} k_{t, T} \\
f_{t, T} \equiv \frac{Y_{T}^{1-v}}{\exp \left(\mu_{T}\right)} R_{t, T}^{1-\sigma}, \\
k_{t, T} \equiv \frac{Y_{T}^{1-v}\left(1+i_{T}\right) \exp \left(u_{T}\right)}{R_{T}} R_{t, T}^{-\sigma},
\end{gathered}
$$

and

$$
R_{t, T} \equiv\left(\frac{R_{t}}{R_{T}}\right)
$$


Second order approximation leads to

$$
\begin{aligned}
F\left(\hat{F}_{t}+\frac{1}{2} \hat{F}_{t}^{2}\right) & =\mathbb{E}_{t} \sum_{T=t}^{\infty}(\beta \phi)^{T-t} f\left(\hat{f}_{T}+\frac{1}{2} \hat{f}_{T}^{2}\right) \\
\hat{F}_{t}+\frac{1}{2} \hat{F}_{t}^{2} & =(1-\beta \phi) \mathbb{E}_{t} \sum_{T=t}^{\infty}(\beta \phi)^{T-t}\left(\hat{f}_{T}+\frac{1}{2} \hat{f}_{T}^{2}\right),
\end{aligned}
$$

and

$$
\hat{K}_{t}+\frac{1}{2} \hat{K}_{t}^{2}=(1-\beta \phi) \mathbb{E}_{t} \sum_{T=t}^{\infty}(\beta \phi)^{T-t}\left(\hat{k}_{T}+\frac{1}{2} \hat{k}_{T}^{2}\right) .
$$

Then, equation (94) can be transformed into

$$
\begin{aligned}
\hat{r}_{t}^{*}= & (1-\beta \phi) \mathbb{E}_{t} \sum_{T=t}^{\infty}(\beta \phi)^{T-t}\left(\hat{k}_{t, T}-\hat{f}_{t, T}\right) \\
& +\frac{1-\beta \phi}{2} \mathbb{E}_{t} \sum_{T=t}^{\infty}(\beta \phi)^{T-t}\left(\hat{k}_{t, T}+\hat{f}_{t, T}\right)\left(\hat{k}_{t, T}-\hat{f}_{t, T}\right) \\
& -\frac{1-\beta \phi}{2} \hat{r}_{t}^{*} \mathbb{E}_{t} \sum_{T=t}^{\infty}(\beta \phi)^{T-t}\left(\hat{k}_{t, T}+\hat{f}_{t, T}\right) .
\end{aligned}
$$

This is because

$$
\frac{1}{2}\left(\hat{F}_{t}-\hat{K}_{t}\right)\left(\hat{F}_{t}+\hat{K}_{t}\right)=-\frac{1-\beta \phi}{2} \hat{r}_{t}^{*} \mathbb{E}_{t} \sum_{T=t}^{\infty}(\beta \phi)^{T-t}\left(\hat{f}_{T}+\hat{k}_{T}\right),
$$

where the higher order terms are ignored.

Equations (95) and (96) are expressed in log exact form as

$$
f_{t, T} \equiv(1-v) \hat{Y}_{T}-\mu_{T}+(1-\sigma) \hat{R}_{t, T},
$$

and

$$
k_{t, T}=(1-v) \hat{Y}_{T}+i_{T}+u_{T}-\hat{R}_{T}-\sigma \hat{R}_{t, T} .
$$


Thus,

$$
\begin{aligned}
\hat{k}_{t, T}-\hat{f}_{t, T} & =i_{T}+\mu_{T}-\hat{R}_{T}-\hat{R}_{t, T} \\
& \equiv \bar{z}_{T}-\hat{R}_{t, T}
\end{aligned}
$$

and

$$
\begin{aligned}
\hat{k}_{t, T}+\hat{f}_{t, T} & =2(1-v) \hat{Y}_{T}+i_{T}-\hat{\mu}_{T}-\hat{R}_{T}+(1-2 \sigma) \hat{R}_{t, T} \\
& \equiv \bar{x}_{T}+(1-2 \sigma) \hat{R}_{t, T} .
\end{aligned}
$$

Then, equation (97) further collapses to

$$
\begin{aligned}
\hat{r}_{t}^{*}= & -\frac{1-\beta \phi}{2} \hat{r}_{t}^{*} Z_{t}+(1-\beta \phi) \mathbb{E}_{t} \sum_{T=t}^{\infty}(\beta \phi)^{T-t}\left(\bar{z}_{T}-\hat{R}_{t, T}\right) \\
& +\frac{1-\beta \phi}{2} \mathbb{E}_{t} \sum_{T=t}^{\infty}(\beta \phi)^{T-t}\left[\bar{x}_{T}+(1-2 \sigma) \hat{R}_{t, T}\right]\left(\bar{z}_{T}-\hat{R}_{t, T}\right) .
\end{aligned}
$$

where

$$
Z_{t} \equiv \mathbb{E}_{t} \sum_{T=t}^{\infty}(\beta \phi)^{T-t}\left[\bar{x}_{T}+(1-2 \sigma) \hat{R}_{t, T}\right]
$$

With equations:

$$
\begin{aligned}
& \frac{\beta \phi \hat{r}_{t+1}^{*}}{1-\beta \phi}=-\frac{\beta \phi}{2} \hat{r}_{t+1}^{*} Z_{t+1}+\beta \phi \mathbb{E}_{t} \sum_{T=t+1}^{\infty}(\beta \phi)^{T-(t+1)}\left(\bar{z}_{T}-\hat{R}_{t+1, T}\right) \\
&+\frac{\beta \phi}{2} \mathbb{E}_{t} \sum_{T=t+1}^{\infty}(\beta \phi)^{T-(t+1)}\left[\bar{x}_{T} \bar{z}_{T}-\bar{x}_{T} \hat{R}_{t+1, T}+(1-2 \sigma) \hat{R}_{t+1, T} \bar{z}_{T}-(1-2 \sigma) \hat{R}_{t+1, T}^{2}\right], \\
& \hat{k}_{t+1, T}-\hat{f}_{t+1, T}=\bar{z}_{T}-\hat{R}_{t+1, T},
\end{aligned}
$$

and

$$
\hat{r}_{t+1}^{*}=\hat{K}_{t+1}-\hat{F}_{t+1}=\mathbb{E}_{t} \sum_{T=t+1}^{\infty}(\beta \phi)^{T-(t+1)}\left(\bar{z}_{T}-\hat{R}_{t+1, T}\right)
$$


Equation (98) is further transformed into

$$
\begin{aligned}
\frac{\hat{r}_{t}^{*}}{1-\beta \phi}= & \bar{z}_{t}+\mathbb{E}_{t} \frac{\beta \phi\left(\hat{r}_{t+1}^{*}+\hat{R}_{t+1, t}\right)}{1-\beta \phi}+\frac{\bar{x}_{t} \bar{z}_{t}}{2} \\
& -\frac{\hat{r}_{t}^{*} Z_{t}}{2}+\mathbb{E}_{t} \frac{\beta \phi Z_{t+1}\left(\hat{r}_{t+1}^{*}+\hat{R}_{t+1, t}\right)}{2} \\
& -\mathbb{E}_{t} \frac{\beta \phi(1-2 \sigma) \hat{r}_{t+1}^{*} \hat{R}_{t+1, t}}{2(1-\beta \phi)}-\mathbb{E}_{t} \frac{\beta \phi(1-2 \sigma) \hat{R}_{t+1, t}^{2}}{2(1-\beta \phi)} .
\end{aligned}
$$

Second order approximation of equations (78) and (93) leads to

$$
r_{t}^{*} \approx \frac{\phi \hat{R}_{t, t-1}}{1-\phi}-\frac{(1-\sigma) \phi \hat{R}_{t, t-1}^{2}}{2(1-\phi)^{2}} .
$$

Substitution of the approximated equation (101) into (100) results in

$$
\begin{aligned}
& \hat{R}_{t, t-1}-\frac{(1-\sigma) \hat{R}_{t, t-1}^{2}}{2(1-\phi)}+\frac{(1-\beta \phi) \hat{R}_{t, t-1} Z_{t}}{2}+\frac{\sigma \hat{R}_{t, t-1}^{2}}{2} \\
= & \frac{(1-\beta \phi)(1-\phi)}{\phi} \mathbb{E}_{t} \sum_{T=t}^{\infty} \beta^{T-t} \bar{z}_{T} \\
& +\frac{(1-\beta \phi)(1-\phi)}{2 \phi} \mathbb{E}_{t} \sum_{T=t}^{\infty} \beta^{T-t} \bar{x}_{T} \bar{z}_{T} \\
& +\frac{\sigma}{2} \mathbb{E}_{t} \sum_{T=t}^{\infty} \beta^{T-t} \hat{R}_{T, T-1}^{2}
\end{aligned}
$$

On the other hand, $Z_{t}$ in (99) can be expressed recursively as

$$
Z_{t}=\bar{x}_{t}+\mathbb{E}_{t} \frac{\beta \phi(1-2 \sigma) \hat{R}_{t+1, t}}{1-\beta \phi}+\beta \phi Z_{t+1}
$$


Finally, solving equations (102) and (103) at time 0 leads to

$$
\begin{aligned}
& \bar{K}_{0}=\frac{(1-\beta \phi)(1-\phi)}{\phi} \mathbb{E}_{t} \sum_{t=0}^{\infty} \beta^{t}\left(i_{t}+\mu_{t}+u_{t}-\hat{R}_{t}\right) \\
& +\frac{(1-\beta \phi)(1-\phi)}{2 \phi} \mathbb{E}_{t} \sum_{t=0}^{\infty} \beta^{t}\left(2 \hat{z}_{t}+2(1-v) \hat{Y}_{t}+i_{t}-\hat{\mu}_{t}-\hat{R}_{t}\right)\left(i_{t}+\mu_{t}+u_{t}-\hat{R}_{t}\right) \\
& +\frac{\sigma}{2} \mathbb{E}_{t} \sum_{t=0}^{\infty} \beta^{t}\left(\hat{R}_{t}-\hat{R}_{t-1}\right)^{2}
\end{aligned}
$$

where

$$
\bar{K}_{0}=\hat{R}_{0,-1}-\frac{(1-\sigma) \hat{R}_{0,-1}^{2}}{2(1-\phi)}+\frac{(1-\beta \phi) \hat{R}_{0,0-1} Z_{0}}{2}+\frac{\sigma \hat{R}_{0,0-1}^{2}}{2} .
$$

Thus,

$$
\begin{aligned}
& \mathbb{E}_{t} \sum_{t=0}^{\infty} \beta^{t}\left(i_{t}+\mu_{t}+u_{t}-\hat{R}_{t}\right) \\
\approx & \mathbb{E}_{t} \sum_{t=0}^{\infty} \beta^{t}\left\{\begin{array}{c}
-\left[(1-v) \hat{Y}_{t}\right]\left(i_{t}-\hat{\mu}_{t}-\hat{R}_{t}\right)-\frac{1}{2}\left(i_{t}+\mu_{t}-\hat{R}_{t}\right)^{2} \\
-\frac{\sigma \phi}{2(1-\beta \phi)(1-\phi)}\left(\hat{R}_{t}-\hat{R}_{t-1}\right)^{2}
\end{array}\right\} .
\end{aligned}
$$

